\title{
Market risk when hedging a global credit portfolio
}

\author{
Alvaro Chamizo \\ BBVA \\ Alfonso Novales \\ Instituto Complutense de Análisis Económico (ICAE), and \\ Department of Economic Analysis, Facultad de Ciencias Económicas y Empresariales, \\ Universidad Complutense, Madrid, Spain
}

\begin{abstract}
Hedging a credit portfolio using single name CDS is affected by high spread volatility that induces continuous changes in a portfolio mark to market, which is a nuisance. Often, the problem is that CDS on firms in the portfolio are not being traded. To get around that, a derivative portfolio can be hedged by taking a contrary position in a creditindex, and we examine in this paper the efficiency of such an imperfect hedge. We find over the 2007-2012 period an 80\% hedging efficiency for a European portfolio, $60 \%$ for North American and Japanese portfolios, and around $70 \%$ for a global portfolio, as measured by the reduction in mark-to-market variance. We also consider sectorial credit portfolios for Europe and North America, for which hedging efficiency is not as high, due to theirmore important idiosyncratic component. Taking into account the quality of the credit counterpart improves the effectiveness of the hedge, although it requires using less liquid credit indices, with higher transaction costs. Standard conditional volatility models provide similar results to the least squares hedge, except for extrememarket movements. An efficienthedge for a creditportfolio madeup of themost idiosyncratic firms would seem to require more than 50 firms, while the hedge for portfolios made up of the less idiosyncratic firms achieves high efficiency even for a small number of firms. The efficiency of the hedge is higher when portfolio volatility is high and also when short term interest rates or exchange rate volatility are high. Increases in VIX, in the 10-year swap rate or in liquidity risk tend to decrease hedging efficiency. Credit indices offer a moderately efficient hedge for corporate bond portfolios, which we have examined with a reduced sample of firms over 2006-2018. This analysis also shows that the current efficiency of a credit index hedge has recovered at pre-crisis levels.
\end{abstract}

Keywords Market Risk, CDS, Credit Indices, Credit Hedge, Asset Allocation, Systemic Risk

JEL classification: G01, G12, G13, G14, G15

\section{Working Paper no 1928}

September, 2019

COMPLUTENSE

MADRID

ISSN: 2341-2356

WEB DE LA COL ECCIÓN: http://www.ucm.es/fundamentos-analisis-economico2/documentos-de-trabajo-del-icaeWorking papers are in draft form and are distributed for discussion. It may not be reproduced without permission of the author/s. 


\title{
Market risk when hedging a global credit portfolio
}

\author{
Authors: \\ Álvaro Chamizo ${ }^{1} 2$ \\ Alfonso Novales ${ }^{3}, 4$
}

\section{Abstract}

Hedging a credit portfolio using single name CDS is affected by high spread volatility that induces continuous changes in a portfolio mark to market, which is a nuisance. Often, the problem is that CDS on firms in the portfolio are not being traded. To get around that, a derivative portfolio can be hedged by taking a contrary position in a credit index, and we examine in this paper the efficiency of such an imperfect hedge. We find over the 2007-2012 period an $80 \%$ hedging efficiency for a European portfolio, $60 \%$ for North American and Japanese portfolios, and around $70 \%$ for a global portfolio, as measured by the reduction in mark-to-market variance. We also consider sectorial credit portfolios for Europe and North America, for which hedging efficiency is not as high, due to their more important idiosyncratic component. Taking into account the quality of the credit counterpart improves the effectiveness of the hedge, although it requires using less liquid credit indices, with higher transaction costs. Standard conditional volatility models provide similar results to the least squares hedge, except for extreme market movements. An efficient hedge for a credit portfolio made up of the most idiosyncratic firms would seem to require more than 50 firms, while the hedge for portfolios made up of the less idiosyncratic firms achieves high efficiency even for a small number of firms. The efficiency of the hedge is higher when portfolio volatility is high and also when short term interest rates or exchange rate volatility are high. Increases in VIX, in the 10-year swap rate or in liquidity risk tend to decrease hedging efficiency. Credit indices offer a moderately efficient hedge for corporate bond portfolios, which we have examined with a reduced sample of firms over 2006-2018. This analysis also shows that the current efficiency of a credit index hedge has recovered at pre-crisis levels.

JEL classification: G01, G12, G13, G14, G15

Keywords: Market Risk, CDS, Credit Indices, Credit Hedge, Asset Allocation, Systemic Risk.

\footnotetext{
${ }^{1}$ Álvaro Chamizo: BBVA. e-mail: alvaro.chamizo@bbva.com.

${ }^{2}$ This article reflects the opinions of the authors, but not the opinion of BBVA.

${ }^{3}$ Alfonso Novales, Instituto Complutense de Análisis Económico (ICAE) and Departamento de Análisis Económico, Facultad de Ciencias Económicas y Empresariales, Campus de Somosaguas, Universidad Complutense (28223 Madrid). Financial support by grants ECO2015-67305-P, PrometeoII/2013/015, Programa de Ayudas a la Investigación from Banco de España is gratefully acknowledged.

${ }^{4}$ The authors acknowledge comments received from J. De Juan Herrero
} 


\title{
Market risk when hedging a global credit portfolio
}

\begin{abstract}
Hedging a credit portfolio using single name CDS is affected by high spread volatility that induces continuous changes in a portfolio mark to market, which is a nuisance. Often, the problem is that CDS on firms in the portfolio are not being traded. To get around that, a derivative portfolio can be hedged by taking a contrary position in a credit index, and we examine in this paper the efficiency of such an imperfect hedge. Over the 2007-2012 period we find an 80\% hedging efficiency for a European portfolio, $60 \%$ for North American and Japanese portfolios, and around $70 \%$ for a global portfolio, as measured by the reduction in mark-to-market variance. We also consider sectorial credit portfolios for Europe and North America, for which hedging efficiency is not as high, due to their more important idiosyncratic component. Taking into account the quality of the credit counterpart improves the effectiveness of the hedge, although it requires using less liquid credit indices, with higher transaction costs. Standard conditional volatility models provide similar results to the least squares hedge, except for extreme market movements. An efficient hedge for a credit portfolio made up of the most idiosyncratic firms would seem to require more than 50 firms, while the hedge for portfolios made up of the less idiosyncratic firms achieves high efficiency even for a small number of firms. The efficiency of the hedge is higher when portfolio volatility is high and also when short term interest rates or exchange rate volatility are high. Increases in VIX, in the 10-year swap rate or in liquidity risk tend to decrease hedging efficiency. Credit indices offer a moderately efficient hedge for corporate bond portfolios, which we have examined with a reduced sample of firms over 2006-2018. This analysis also shows that the current efficiency of a credit index hedge has recovered at pre-crisis levels.
\end{abstract}

JEL classification: G01, G12, G13, G14, G15

Keywords: Market Risk, CDS, Credit Indices, Credit Hedge, Asset Allocation, Systemic Risk.

\section{Introduction}

The concentration risk of a credit portfolio comes from two limitations of diversification. The first one, name concentration, relates to an imperfect diversification of idiosyncratic risk in the portfolio either because of its small size or because of large exposures to specific individual obligors. The second one, sector concentration, relates to imperfect diversification across the systematic components of risk in sectorial factors (see BCBS (2006)). The concentration risk is one of the main worries of 
credit managers and regulators. ${ }^{1}$ Indeed, a recent survey regarding credit portfolio managers' objectives suggested a strong emphasis on addressing the structure of the portfolio and risk identification, showing a slightly lower emphasis on managing regulatory change and specific regulations. Objectives cited by more than $50 \%$ of bank respondents include addressing portfolio risks through portfolio structure/concentrations and limits (91\%) (see Leung et al. (2017)).

When the exposure exceeds from a given level of concentration determined by its risk appetite framework, a bank can increase its credit business by appropriately hedging the credit portfolio. Besides, the high volatility of CDS spreads induces continuous changes in a credit portfolio mark to market, which is a nuisance. To get around that, a derivative portfolio can be hedged by taking a contrary position in the CDS of the credit counterparts, when CDS have been issued on them. Unfortunately, commercial banks often lack single name CDS contracts to be used in a hedge for the credit portfolio of small and medium businesses, and a macro hedge with a credit index will be needed. Even when the appropriate CDS contracts exist, the low liquidity of the CDS market, with high costs to entering and leaving the market, has led Treasury departments at financial institutions to use a very liquid CDS from a similar firm or a credit index as hedging instrument. An additional difficulty came up when the financial crisis brought a drastic decrease in volume traded at single name CDS contracts, threatening to reduce the correlation between single name CDSs and credit indices and to increase the level of market risk in CVA risk hedging. Indeed, negotiation of credit derivatives declined more or less steadily since 2007. The negotiated volume fell to $\$ 16$ trillion at end-December 2014 from a peak of $\$ 58$ trillion at end-2007. The market value of CDS also continued to decline, to $\$ 593$ billion at end-December 2014 in gross terms and $\$ 136$ billion in net terms. ${ }^{2}$

As a consequence of the possible lack of CDS contracts, their high volatility, or the imperfect correlation with credit indices, index hedging leaves some market risk that will be even more important when CDS contracts have not been issued on the counterpart, as it is often the case in commercial banks' credit portfolios. Precisely, the objective of this paper is to analyze the empirical market risk that remains in a CDS portfolio due to the imperfect correlation between the underlying portfolio to be replicated and the credit index involved in a dynamic replication strategy. Our estimates of the hedging efficiency of credit indices should serve as a lower bound for evaluating more complex strategies, as when we face problems related to maturity mismatch, stochastic exposure, or lack of information on the credit spread of the firm. Even though we work with CDS spreads quoted in the market, our results can also serve as a good reference for more illiquid CDS or for firms for which CDS contracts have not been issued.

\footnotetext{
${ }^{1}$ As pointed out recently by D. Nouy, among many others: "Banks also need to work on how they calculate and actually apply limits [...] What we often see is that risk limits are in place but they do not sufficiently constrain risk-taking. The reason is that the limits are often set so high that there's virtually no possibility of breaching them. This calls into question the entire risk appetite framework." (speech by Danièle Nouy, Chair of the Supervisory Board of the ECB, at the International Conference on Banks' Risk Appetite Frameworks, Ljubljana, 10 April 2018).

${ }^{2}$ The net measure takes account of bilateral netting agreements covering CDS contracts but, unlike gross credit exposures, is not adjusted for cross-product netting [see BCBS (2015)]. In addition to the financial crisis, the Big Bang Protocol, a standardization process for CDS introduced in 2009, was behind the fall in the notional value of CDS contracts Markit (2009).
} 
We consider equally-weighted regional portfolios for Europe, North America and Japan, as well as equally-weigthed sectorial portfolios for Europe and North America, as described in the data section below. We address the following issues: What is the level of market risk? Is market risk higher for North American portfolios than for European portfolios? Does the effectiveness of the hedge increase when we consider the firm's rating in choosing the credit index for the hedge? How does the level of market risk of corporate debt compares to that of a CDS portfolio?

We start with a single-index least squares hedging strategy based on credit indices: Europe Main iTraxx, CDX, and Japanese iTraxx, each for the corresponding regional portfolio. Even though the financial crisis reduced correlations between single name CDSs and credit indices, we show that they still allowed for a relatively efficient hedge. Hedge efficiency is higher for the European portfolio than for North American or Japanese portfolios. Over the whole sample, the hedge achieves a reduction in the variance of the portfolio's profit and losses (P\&L), measured by the change in its mark-to-market (MtM) value, of $80 \%$ for a European portfolio, $60 \%$ for North American and Japanese portfolios, and around $70 \%$ for a global portfolio. The hedge is more efficient in tranquil periods (before 2008 and after 2010) than during the crisis period. In an extended sample for 2006-2018, albeit with less firms, we obtain that hedge efficiency has recovered to pre-crisis levels.

Hedging efficiency is heterogeneous across sectors and, for similar sectors, it is higher in Europe than in North America. For the 2006-2012 period, the median reduction in the portfolio's profit and losses is $45 \%$ for the European sectors and $30 \%$ for the North American sectors, although it is almost twice as large in tranquil periods ( $70 \%$ and $43 \%$, respectively) than it was during the crisis. Variance reduction figures clearly show that sectorial portfolios have much higher idiosyncratic risk than regional portfolios.

Idiosyncratic risk does not offset among the different CDS contracts even in large size portfolios, although we show that the efficiency of the hedge depends on the nature of the firms included in the portfolio. Indeed, if we include the more idiosyncratic firms, we need more than 50 firms to achieve some significant efficiency, with a Herfindahl concentration index above $2 \%$. On the other hand, if the portfolio includes the more systemic firms, the hedge achieves significant efficiency even for small portfolios.

Some alternative strategies improve these results slightly at the cost of using credit indices that are less liquid, with higher transaction costs. DCC estimates of the hedge ratio are more volatile, leading to higher entry and exit costs to adjust the hedge continuously. The DCC hedge might be optimal in market situations of high volatility, while performing similarly to the least squares hedge over the course of an economic cycle.

Our analysis could also be taken as an element in the estimation of CVA credit risk, even though we have not considered important factors as the stochastic exposure of derivatives, the netting of the credit positions or the role of the clearing house. Basel III required the computation of the capital 
charge for CVA risk of each credit position, which can be determined by the CDS spread of the credit counterpart, taken as the market estimate of the expected loss from the credit trade (see BCBS (2011) and Hull (2012), Chapter 17). ${ }^{3}$

The paper is divided into eight sections: In Section 2 we describe our dataset. In Section 3 we outline the framework we have followed for the hedge and the different hypotheses considered. In Section 4 we present the results of the hedge methodologies in sectorial and regional portfolios. Section 5 contains a variety of tests to analyze the robustness of our results. In Section 6 we analyze the determinants of hedging efficiency. In Section 7 we evaluate the more recent hedging efficiency and examine the possibility of hedging corporate bond portfolios using a credit index. Finally, we lay out the main conclusions in Section 8.

\section{Input data}

Our sample covers runs from 2006 to 2012, a most relevant period of time for the credit market, given the events that took place as a consequence of the financial crisis. We use a sector classification based on the ICB criteria, (Industry Classification Benchmark), which distinguishes four levels: Industry, supra-sector, sector and subsector. We use daily data from Markit, a database organized at the industry level, with eleven industries defined by the ICB criteria: financials, health care, energy, telecommunication services, basic materials, utilities, industrials, technology, consumer goods, and consumer services. We consider senior 5-year CDS contracts with the standard currency and restructuring clause because of their liquidity and representativeness. We include in our sample CDS contracts that have a quoted price every day over the 2006-2012 period, with a total of 722 firms. The different geographical regions contained in the Markit database are: Africa, Asia, Caribbean, Eastern Europe, Europe, India, Latin America, Middle East, North America, Oceania, Offshore, Pacific and Supra. However, most of these 722 firms are located in Europe, North America and Asia. Table 1 summarizes the distribution of firms by industry and region.

To hedge equally-weighted sectorial and regional credit portfolios we consider the iTraxx Europe, iTraxx Europe Crossover and HiVol iTraxx Indices to hedge the European portfolio, the CDX NA IG and High Yield CDX Indices to hedge the North American portfolio, and the Japan Main Index for the Japanese portfolio. We will also consider using combinations of credit indices for the hedge. The iTraxx Europe index is used to hedge European sectorial portfolios, while the CDX NA IG index is used for sectorial North American portfolios.

\section{(INSERT HERE TABLE 1)}

\footnotetext{
${ }^{3} \mathrm{CVA}$ is the adjustment by credit valuation of a derivative portfolio. In the absence of a CDS for the credit counterpart, a proxy spread based on the rating, industry and region of each counterparty has been suggested, which can be obtained by estimation of credit spread curves the rating, sector and region of each counterparty as factors (BCBS (2012)).
} 
We additionally use a 2006-2018 sample to check on the time evolution of hedge efficiency. This second sample contains a much lower number of firms because the filters applied to the selection of firms quickly reduces its number as the sample length increases. We consider CDS and corporate bond data from these firms to test the possibility that, in the absence of relatively liquid instruments, a hedging strategy with credit indices might provide some coverage against corporate bond risk as well as against iliquid instruments as bank loans and financial guarantees.

\section{A framework for the hedge}

To calculate the mark-to-market of a CDS portfolio we assume that in the initial period we have invested one monetary unit (euro, US dollar or yen) in each CDS contract in a given region or sector. We are therefore long in the credit market, as it is natural for a financial institution, and the portfolio is not changed over the period considered. Hence, our loss in the portfolio will be the result of an increase in the CDS spread of a given firm, and the natural hedge will be to take the opposite position in a given credit index.

For the hedging analysis we take weekly averages of CDS spreads for each contract to avoid an excessive daily market noise, as well as for the six credit indices that we use in the hedge. That leaves us with 365 weekly data points for CDS spreads. ${ }^{4}$

Being long in each CDS contract, we approximate the weekly change in mark-to-market of the CDS for firm $i$ at time $t$ as: ${ }^{5}$

$$
\Delta M t M_{t}^{i}=-\left(C D S_{t}^{i}-C D S_{t-1}^{i}\right) R D_{t}^{i}
$$

where $C D S_{t}^{i}$ and $R D_{t}^{i}$ denote the CDS spread and the risky duration of contract $i$ at time $t$, with:

$$
R D_{t}^{i}=\sum_{t=1}^{m} S_{t} \tau_{t-1, t} D F_{t}
$$

where $S_{t}$ is the survival probability at time $t, \tau$ is the time in years between two consecutive payment dates, $D F_{t}$ is the discount factor at time $t$, and $m$ is the total number of payments in the CDS contract.

To estimate the survival probability $S_{t}$ over the time interval $[x, x+t]$, we use its representation in terms of a "hazard rate" $h$ that we assume to be constant: $S_{t}=e^{-\int_{0}^{t} h(u) d u}=e^{-h t}$ [see Duffie and Singleton (1999)]. Under independence between the exogenous default process and the risk-free rate, the present value of the premium leg of a CDS that is paid continuously would be, $P V_{\text {Premium }}=$ N.CDS. $\int_{0}^{T} D F_{t} . S_{t} d t$ where $N$ and $S_{t}$ denote the notional of the contract and the infinitesimal prob-

\footnotetext{
${ }^{4}$ We also present below the results obtained with daily data, for comparison.

${ }^{5}$ For simplification, we are also assuming that we can roll over CDS contracts and credit indices every week.
} 
ability of survival at time $t$, respectively. The discount factor over the time interval $[x, x+t]$ can be written $D F_{t}=e^{-\int_{0}^{t} r(u) d u}=e^{-r t}$, where $r$ is the instantaneous spot risk-free rate, assumed to be constant over that time interval. On the other hand, the present value of the protection leg of a CDS is $P V_{\text {Protection leg }}=-N(1-R) \int_{0}^{T} D F_{t} . d S_{t}$, where $R$ is the recovery rate. Each week we estimate $h$ for each firm in the sample. The recovery rates are taken from the Markit database. We use the 5-year swap rate for $r$. Therefore, ignoring any accrued interest, the par ("fair") CDS spread, $C D S_{p}$, would be

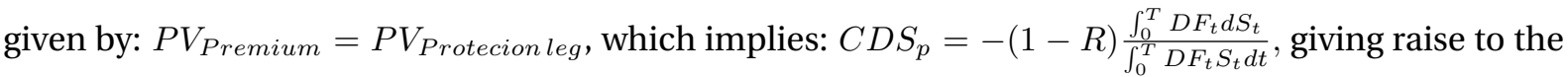
credit triangle relationship: $C D S_{p}=(1-R) h \frac{\int_{0}^{T} D F_{t} e^{-h t} d t}{\int_{0}^{T} D F_{t} e^{-h t} d t} \Rightarrow h=\frac{C D S_{p}}{1-R}$ [for further details, see White (2013)].

Thus, if we assume that the payment of the premium leg takes place in continuous time, we can approximate the risky duration each week over the sample period for a given CDS contract by:

$$
R D^{i}=\int_{0}^{T} \exp \left[-\left(C D S^{i} /\left(1-R^{i}\right)+r\right) t\right] d t=\frac{1-\exp \left[-\left(C D S^{i} /\left(1-R^{i}\right)+r\right) T\right]}{C D S^{i} /\left(1-R^{i}\right)+r}
$$

where $R^{i}$ is the recovery rate for contract $i$ at time $t$, and $T$ is the tenor, which is five years in our case.

For an unhedged equally-weighted portfolio we obtain the weekly change in mark-to-market at $t$ time as,

$$
\Delta M t M_{t}^{p}=\frac{1}{n} \sum_{i=1}^{n} \Delta M t M_{i}
$$

where $n$ is the total number of firms in the portfolio.

The weekly change in mark-to-market for each credit index is obtained similarly to the one for single names in equation (3.1):

$$
\Delta M t M_{t}^{\text {Index }}=-\left(\text { Spread }_{t}^{\text {Index }}-\text { Spread }_{t-1}^{\text {Index }}\right) R D_{t}^{\text {Index }}
$$

We calculate the weekly least-squares hedge ratio for an individual firm or a portfolio with respect to a credit index as,

$$
\begin{aligned}
& \operatorname{Bet}_{t}^{i}=\frac{\operatorname{Cov}\left(\Delta M t M_{t}^{i}, \Delta M t M_{t}^{I n d e x}\right)}{\operatorname{Var}\left(\Delta M t M_{t}^{I n d e x}\right)}=\rho\left(\Delta M t M_{t}^{i}, \Delta M t M_{t}^{I n d e x}\right) \frac{\operatorname{Std} \cdot \operatorname{Dev}\left(\Delta M t M_{t}^{i}\right)}{\operatorname{Std} \cdot \operatorname{Dev}\left(\Delta M t M_{t}^{I n d e x}\right)} \\
& \operatorname{Bet}_{t}^{p}=\frac{\operatorname{Cov}\left(\Delta M t M_{t}^{p}, \Delta M t M_{t}^{\text {Index }}\right)}{\operatorname{Var}\left(\Delta M t M_{t}^{\text {Index }}\right)}=\rho\left(\Delta M t M_{t}^{p}, \Delta M t M_{t}^{I n d e x}\right) \frac{\operatorname{Std} \cdot \operatorname{Dev}\left(\Delta M t M_{t}^{p}\right)}{\operatorname{Std} \cdot \operatorname{Dev}\left(\Delta M t M_{t}^{\text {Index }}\right)}
\end{aligned}
$$

where $\rho$ denotes the linear correlation coefficient and Cov, Std.Dev, denote the covarianza and standard deviation operators, respectively. The least squares estimate of the ratio can be written as the 
product of two factors: the linear correlation coefficient between the portfolio and the credit index, and the relative volatility of portfolio and index. Hence, a beta estimate above 1 necessarily means that the volatility of spreads for the portfolio or sector under consideration is higher than the observed credit index volatility. On the other hand, a perfect correlation between credit portfolio and index does not imply a unit hedge ratio, the beta coefficient then being equal to the relative volatility of the portfolio and the credit index.

Using rolling windows we end up with 313 weekly estimates for $B e t a^{i}$ or $B e t a^{p}$, running from January 2007 to December 2012. The weekly change in mark-to-market at $t$ time for a hedged portfolio or for a single CDS contract is obtained as:

$$
\Delta \widetilde{M t M_{t}^{i}}=\Delta M t M_{t}^{i}-\operatorname{Beta}_{t}^{i}\left(\Delta M t M_{t}^{I n d e x}\right)
$$

$$
\Delta \widetilde{M t M_{t}^{p}}=\Delta M t M_{t}^{p}-\operatorname{Beta}_{t}^{p}\left(\Delta M t M_{t}^{I n d e x}\right)
$$

Finally, we can calculate the accumulated mark-to-market at time $T$ for an unhedged or a hedged portfolio by aggregating over time the weekly change in mark-to-market from a given point in time, which we will usually take it to be the beginining of the hedging exercise.

\section{Hedging results}

In this section we describe the hedging analysis of equally-weighted sectorial and regional portfolios.

\subsection{Sectorial portfolios}

Figure 1 shows sectorial medians of the correlations between individual contracts and the European iTraxx, taken as hedge credit index, during 2007-2012. They experienced a drastic elevation in July 2007 for all sectors, reflecting the increased correlation across the credit market at that point. Correlations decreased after the Lehman crisis, possibly due to the fact that a fall in volume traded in single names at the time reduced the connection between individual CDS spreads and the credit index. Correlations with the credit index increased again in 2010, having a second reduction episode during the European sovereign crisis in the summer of 2011. In the last part of the sample, the technology sector decoupled from the rest of the sectors as well as from the credit index. 
(INSERT HERE FIGURE 2 )

Sectorial hedge ratios for the European portfolio are represented in Figure 2 as the median of beta estimates for the individual firms in each sector. Hedge ratios across sectors display more important differences than correlation coefficients, reflecting the large differences in sectorial spread volatility. Energy and health care were the sectors with the lowest beta during the crisis, while basic materials was the sector with the highest beta, although with a noticeable decrease from 2010 onwards. The evolution of the financial sector beta is particularly interesting. It was very low before the crisis but it experienced a sudden increase at the beginning of the summer of 2007, before the first symptoms of the crisis became apparent. In September 2009 hedge ratios for the financial sector started again an increasing trend, while median betas for the other sectors were either stable or decreasing. Clearly, the global crisis was overall a financial global crisis. These results are also interesting for asset allocation purposes, as they give a clear sign of the level of systemic risk in the different sectors.

\section{(INSERT HERE TABLE 2)}

Table 2 shows sectorial hedge ratios, the sectorial correlation with the credit index (iTraxx) and the relative volatility of sectorial MtM and index MtM for European firms. In spite of being median values across the firms in the sector, they provide a quite approximate decomposition of sectorial hedge ratios. ${ }^{6}$ At the level of the sector, correlations with the credit index generally increased during the financial crisis, and remain after the crisis above their pre-crisis levels. ${ }^{7}$

Finally, Figure 3 displays hedge ratios for the North American portfolio, and their decomposition between index correlation and relative volatility is presented in Table 3 Here, the financial sector had the highest beta since the end of 2007, while the health care sector was the one with the lowest beta, as in Europe. The time evolution of the correlations with the index (Figure 4) is similar to the one observed in Europe although at lower levels, suggesting that, in spite of being constructed from credit securities issued by North American firms, CDX does not provide as good a hedge for the US credit portfolio as iTraxx for the European portfolio. That might be an indication of larger idiosyncratic components of credit risk in North American firms than in European firms.

\section{(INSERT HERE FIGURE 3)}

\section{(INSERT HERE TABLE 3 )}

\section{(INSERT HERE FIGURE 4)}

Table 4 shows the efficiency of hedging sectorial portfolios with a credit index, as measured by the reduction in weekly mark-to-market variance. A moderate hedging efficiency can be achieved for

\footnotetext{
${ }^{6}$ That is, the hedge ratio is approximately equal to the product of the correlation between the sector median and the market index, and their relative volatility. This would hold as an exact equality for any individual firm.

${ }^{7}$ This may be consistent with the growing fear in the financial industry we mentioned in the Introduction, that the correlation between CDS indices and single-name contracts was in danger of breaking down as a consequence of diminished single-name traded volumes and an increase in the notional outstanding in index CDS products.
} 
European portfolios over the full sample, except for the technology and utilities sectors. However, we can see that the efficiency was much higher before the crisis. The hedge performed again better after the crisis, without reaching the pre-crisis efficiency levels for a while. Changes in correlations over the three periods were not large, while some of the increases in sector volatility relative to the index were quite substantial during the crisis. Hedging efficiency is lower for North American sectors. Furthermore, the sectors with the most or the least efficient hedge are different in North America and Europe.

\section{(INSERT HERE TABLE 4 )}

The correlation coefficients in the lower part of Table 2 show that European hedge ratios are mainly determined by the relative volatility between the sector and the index, with the correlation between them playing a minor role. Even of more consequence is the fact that the hedging efficiency seems to be determined by the sectorial correlation with the credit index, with relative volatility being almost irelevant. Hedging efficiency is also unrelated to the size of the hedge ratio. This has been consistently the case for the three subperiods considered, and specially in the crisis and post-crisis periods. The result is not so clear for the North American portfolios, with hedging efficiency being related to both, the porfolio-index correlation and their relative volatility, although the former effect is dominant.

\subsection{Regional portfolios}

\subsubsection{European CDS portfolio analysis}

We now examine weekly profit and losses (P\&L) for the European equally-weighted CDS portfolio of 246 firms together with the P\&L that would have prevailed under a weekly hedge for the period 2007-2012. Figure 5 is a scatterplot of returns of the unhedged portfolio versus the returns that would have been achieved with a hedging position in the iTraxx index, as given by the product $\operatorname{Beta}_{t}^{i}\left(\Delta M t M_{t}^{i \operatorname{Traxx}}\right)$. Similarity between both returns indicates a good hedge. In the graph we distinguish between the pre-crisis, crisis and post-crisis periods. The huge deterioration in the credit market during the crisis is evident, with occasional losses over 100 basis points (b.p.) for the whole European portfolio. Downside market movements are smaller than those of the unhedged portfolio, and the hedge with the iTraxx Europe index works well overall. The main problem with this hedge is indicated by the points indicating a loss from the CDS portfolio simultaneously with a profit from the credit index used in the hedge. That would imply a double loss, as we would have been long in the credit portfolio and short in the credit index.

\section{(INSERT HERE FIGURE 5 )}

Figure 6 displays cumulative weekly P\&L during the period 2006-2012 for the unhedged and hedged European credit portfolios. ${ }^{8}$ The graph reflects the general increase in credit spreads over 2006-2012.

\footnotetext{
${ }^{8}$ We have ignored the discount factor when aggregating the P\&L because we want to focus on the pure effect of the hedge of
} 
The devastating effect of the recent crisis in terms of market losses is clear. It is also noteworthy that after some weeks of very high losses, we usually observe an opposite market reaction, possibly because of some active measures from regulators and governments. In terms of hedging efficiency, we must pay attention to three features: i) the size of the wedge between the P\&L of the hedged and unhedged portfolios, ii) whether the P\&L line is smoother for the hedged than for the unhedged portfolio, and iii) the distance between the hedged portfolio line and the horizontal axis at zero, which can be taken as an indication of residual market risk. We can see that losses are clearly reduced by hedging with iTraxx, although the immunization of the portfolio is incomplete, leaving unsecured market risk.

\section{(INSERT HERE FIGURE 6)}

It is also interesting to observe that the hedge worked better in the pre- and post-crisis periods than during the crisis. Over the full sample, the efficiency of the one-index hedge, as measured by the reduction in portfolio variance was $81 \%$, with reductions of $83 \%, 74 \%$ and $91 \%$ over the pre-crisis, crisis and post-crisis periods, as shown in Table 5. As expected, the regional portfolio provides a much better compensation of idiosyncratic risks than the sectorial portfolios.

\section{(INSERT HERE TABLE 5)}

Finally, Figure 7 shows the empirical density (bars, right axis) and distribution functions (lines, left axis) of weekly P\&L for the unhedged and hedged European portfolios. The red and blue lines give us the historical probability of having a loss higher than the value shown in the $\mathrm{X}$-axis. These estimates are very relevant to establish a VaR limit or a stop loss on market risk. We can choose a desired probability level on the left axis (95\%, for instance), bring it to the red and blue lines, and the projection on the X-axis would give us the weekly P\&L VaR estimate. ${ }^{9}$

\section{(INSERT HERE FIGURE 7)}

The efficiency of the hedge can also be seen in Table 6, where we present the estimated probabilities of a fall in mark-to market larger than one or two standard deviations of the unhedged portfolio. For the European portfolio, the hedge achieves a sharp reduction in the probability of a weekly fall larger than one standard deviation, from $15.8 \%$ to just $3.2 \%$. The probability of a fall larger than two standard deviations comes down to almost zero. The reduction can be seen to be very important in the three subperiods, and particularly in the last period. Before the crisis there was a $6 \%$ incidence of a fall larger than one standard deviation, which would have been avoided with the hedge.

\section{(INSERT HERE TABLE 6)}

the credit portfolio and the size of market risk.

${ }^{9}$ To be precise, some interpolation would be needed. 


\subsubsection{North American CDS portfolio analysis}

For the North American portfolio, with 360 firms, the results of the hedge show a pattern similar to the European portfolio. Even though it is more diversified than the European portfolio in terms of the number of firms, the results of the hedge are not as good as in Europe. The scatterplot of weekly markto-market changes and the correlation coefficients in Figure 8 already advanced that the effectiveness of the hedge is higher during the non-crisis periods than during the crisis. Indeed, the reduction in volatility from the one-index hedge was $60 \%$ over the full sample, with reductions of $76 \%, 55 \%$ and $70 \%$ in the pre-crisis, crisis and post-crisis periods, below the ones achieved for the European portfolio in each of the three subperiods. Even though this was a global crisis, the increase in spreads during the crisis was larger in the North American than in the European portfolio. The hedged portfolio seems to work well, achieving a clear reduction of the long- and short-term fluctuations in P\&L of the unhedged portfolio. Figure 9 shows how the hedge concentrate weekly changes in mark-to market into a small interval around the origin, indicating the reduction in the level of risk. Howerver, the level of market risk over the sample period was also larger than in Europe. That bespeaks for the fact that North America was at the time of the Lehman Brothers default the epicenter of the crisis, with a high level of idiosyncratic risk. In fact, market risk at the end of the sample remained high, around 500 b.p., twice as large as in Europe. ${ }^{10}$

\section{(INSERT HERE FIGURE 8)}

(INSERT HERE FIGURE 9 )

\section{(INSERT HERE FIGURE 10)}

The mark-to-market of the hedged North American portfolio has a 5.5\% probability of experiencing a weekly fall larger than one standard deviation of the unhedged portfolio over the full sample, versus a $13.2 \%$ probability for the unhedged portfolio. Such a reduction was again very important in the three subperiods. However, this measure of hedge effectiveness is not as good as the one for the European portfolio, again expressing a higher level of unsecured market risk in North America. That suggests that there is higher undiversifiable credit risk in the North American than in the European credit market, for which credit indices do not offer a good hedge.

\subsubsection{Japanese CDS portfolio analysis}

Results for the Japanese credit portfolio, made up of 116 firms, are qualitatively similar to the other two regions, showing the global nature of the credit crisis. Losses from the unhedged portfolio were often below 100 b.p., although it is also true that the level of Japanese spreads is also generally lower than in the rest of the world.

\footnotetext{
${ }^{10}$ This is measured by the distance between the P\&L for the hedged portfolio (green line) and the horizontal axis in Figure 10.
} 
The unhedged and hedged portfolios both had almost zero P\&L before the crisis, indicating stable credit spreads. They experienced the large increase in credit spreads during the 2006-2012 period that is also observed in the other regions. The hedge was quite successful in isolating the portfolio from the increased widening of spreads after 2007, with the accumulated P\&L of the hedged portfolio being well above the one for the unhedged portfolio. It also achieved a low level of market risk, well below the levels in Europe and North America. Up to 2009 the effectiveness of the hedge seems higher than in European and North American portfolios. However, after 2009, the degree of immunization with respect to the P\&L of the unhedged portfolio was minimal, and in 2012 market risk was at a level similar to Europe. The reduction in volatility was $60 \%$ over the full sample from the one-index hedge, with reductions of $63 \%, 60 \%$ and $59 \%$ during the pre-crisis, crisis and post-crisis periods. The overall efficiency of this hedge is similar to that in North America, just because of the better performance during the crisis. In the pre-crisis and post-crisis periods, the hedge did not work as well as in North America or Europe.

The hedge barely reduces the probability of a fall larger than one standard deviation in mark-tomarket to $7.1 \%$ over the full sample, higher than the similar probabilities for the European and North American portfolios. On the other hand, the probability of a fall above two standard deviations is $1.6 \%$ for the Japanese hedged portfolio, below the similar probability for the North American portfolio, showing that the hedge worked quite well on the extreme tail [see Table 6]

\subsubsection{Global CDS portfolio analysis}

As a last exercise, we show the results of the aggregate global portfolio, considering an equal exposure to each firm in Europe, North America and Japan. We ignore the effect of foreign exchange rates, as we want to focus just on the ability to immunize a global credit portfolio against credit market fluctuations. ${ }^{11}$ It is relevant that we are now considering a portfolio of 722 firms, a higher diversification that should lead us to expect that the hedge should work better than in single regions. However, in general terms, the results are a bit worse than in the European portfolio, due to the influence of the North American firms in the global portfolio and to the high correlation among the worst individual firms from different regions at the end of 2008 (Lehman default). Consequently, the benefits from diversification decrease. The efficiency of the one-index hedge was $71 \%$ over the full sample, with variance reductions of $82 \%, 67 \%$ and $80 \%$ over the pre-crisis, crisis and post-crisis periods.

The wedge between the accumulated P\&L for the unhedged and hedged portfolios is analogous to the one in Europe. The same can be said for the level of market risk, as measured by the level of accumulated P\&L for the hedged portfolio. The probability of having a large mark-to-market fall is again sharply reduced by the hedge, in parallel with the reductions for Europe and North America,

\footnotetext{
${ }^{11}$ This is clearly an approximation. An interesting question would be to examine the possibility of hedging both against credit market risk and currency risk, but that goes well beyond the scope of this paper.
} 
and the level of market risk falls between the levels obtained for these two regions. [see Tables 5 and $6]$.

\section{Robustness analysis}

We analyze in this section the possibility of increasing the effectiveness of the hedge by alternative modifications of the least-squares single-index hedge described in the previous section.

\subsection{Hedging with ratings in mind}

We start by considering the possibility of increasing the effectiveness of the hedge by using credit indices according to the credit quality of each firm in the portfolio. We will now use the iTraxx and the HiVol iTraxx indices in the hedge for the European credit portfolio, instead of just using iTraxx, and the CDX and High Yield CDX indices for the North American portfolios, rather than hedging only with the CDX index. Again, we assume that the liquidity of both indices is enough to balance our hedge weekly without any entry or exit cost. Our hedging strategy is now as follows: in a given week, if the firm has an investment grade we use the iTraxx index to hedge its CDS. Otherwise we use the HiVol iTraxx index. In the case of the North American portfolio, we operate similarly, using as an alternative hedge for the non-investment grade CDS contracts the High Yield CDX index. We also consider the Markit iTraxx Europe Crossover index as hedging instrument because of its higher liquidity.

Hedging effectiveness improves somewhat relative to the one-index hedge for the European, North American and global portfolios, but not for the Japanese portfolio. For instance, the reduction in the variance of weekly changes in mark-to-market for the global portfolio over the full sample increases from $71 \%$ to $79 \%$ [see the 'Two-index' rows in Table 5]. The probability of having a weekly loss higher than one or two standard deviations is slightly reduced relative to the use of a single index. The increased efficiency of the two-index hedge arises mainly in the crisis and post-crisis subperiods, being particularly important for the North American and global portfolios, and somewhat less for the European portfolio. This is clearly a hedging strategy that deserves a detailed cost-benefit analysis by risk managers. Not surprisingly, given the portfolio composition, the two-index hedge for the global portfolio behaves as in Europe and North America, producing a significant gain in the crisis and postcrisis periods, but not during the crisis.

\subsection{Dynamic conditional correlation hedging}

The previous analyses have considered a rolling window of 52 weeks to estimate the hedging ratios, so that the correlation and variance estimates have been allowed to change over time. However, a more structured analysis of time-variation in the parameters of the joint distribution for the portfolio and the hedging asset could benefit from conditional variance specifications. In this section we use 
a Dynamic Conditional Correlation (DCC) model under an Exponentially Weighted Moving Average (EWMA) specification Engle (2002) to estimate volatilities and the conditional correlation between the portfolio and the credit index, in order to see if the use of conditional moments can improve the results of the least squares hedge.

If we denote by $r_{i t}$ the return on the CDS contract of firm $i$ at time $t$, we assume the return conditional variance $\sigma_{i t}^{2}$ to follow the EWMA model:

$$
\sigma_{i t}^{2}=\lambda \sigma_{i t-1}^{2}+(1-\lambda)\left(r_{i t-1}-\mu_{i}\right)^{2}, i=1,2, \ldots n
$$

where $\mu_{i}$ is the conditional mean of returns and $n$ is the number of firms in the sample. The DCC model uses standardized returns on different assets: $z_{i t}=\left(r_{i t}-\mu_{i}\right) / \sigma_{i t}, z_{j t}=\left(r_{j t}-\mu_{j}\right) / \sigma_{j t}$ to generate the auxiliary variables:

$$
q_{i j, t+1}=(1-\lambda) z_{i t} z_{j t}+\lambda q_{i j, t}, \forall i, j
$$

and the conditional correlation can be estimated as:

$$
\rho_{i j, t+1}=\frac{q_{i j, t+1}}{\sqrt{q_{i i, t+1}} \sqrt{q_{j j, t+1}}}
$$

Given an unhedged portfolio and the credit index used in the hedge, we get the covariance and the kedge ratio relative to the market index as:

$$
\begin{gathered}
\operatorname{Cov}_{i, \text { index }, t+1}=\rho_{i, \text { index }, t+1} \sqrt{\sigma_{i, t+1}^{2} \sigma_{\text {index }, t+1}^{2}} \\
\text { Beta }_{i, \text { index }, t+1}=\frac{\text { Cov }_{i, \text { index }, t+1}}{\sigma_{\text {inde }, t+1}^{2}}
\end{gathered}
$$

where the conditional volatility for the index is assumed to also follow an EWMA structure similar to the one for individual firms. In this exercise we use again a one-index hedge, with iTraxx as market index for the European portfolio, CDX as market index for the North American portfolio, and the Japanese iTraxx as market index for the Japanese portfolio. We assume $q_{i 0}=1 \forall i$, and we take 
the average of the product $z_{i, t} z_{\text {index }, t}$ of the first 52 observations as initial value $q_{i, \text { index }, 0}$. We establish the parameter $\lambda=0.94$ based on RiskMetrics, Longerstaey and Spencer (1996). Finally, we also take the standard deviation of the first 52 observations as initial value for $\sigma_{i 0}$. Our estimations cover the 2006-2012 period, as with least squares estimates.

Table 5 shows that there are not noticeable differences in the performance of the DCC hedge relative to the least-squares hedge in any of the three subperiods considered or in the full-sample for any of the regional portfolios or for the global portfolio. For the European and North American portfolios, the conditional hedge yields slightly better results than those obtained by the least-squares hedge in specific days of extreme volatility, but without any discernible effect on time aggregate measures of hedging efficiency. ${ }^{12}$ This should be expected, as the DCC model estimates an instantaneous variance at time $t$ by weighting more heavily the recent observations. As a consequence, DCC estimates react more quickly than least squares estimates. This becomes evident when comparing the sectorial median hedge ratios estimated by the DCC model, which turn out to be more irregular than least-squares hedge ratios in Figure 2. DCC estimates also reduce slightly the probability of getting a large fall in mark-to-market for the European portfolio, but not for the North American portfolio.

\subsection{Daily hedge results}

We analyze now the possibility of rebalancing the hedge daily assuming again that the cost of entry to the market is zero. In this case we estimate the hedge beta for each firm using a single credit index with a window of 252 daily data. As shown in Table 5, the daily hedge performs relatively well for the European and global portfolios, with a noticeable reduction in the variance of weekly CDS spread changes, especially in the periods before and after the crisis. The daily hedge does not perform so well for the North American portfolio or the Japan portfolios. The hedge is again able to reduce significantly the probability of a fall in CDS spreads larger than one or two standard deviations.

The numerical reduction in mark-to-market variance is not strictly comparable with the results obtained under the weekly hedge, but the lower variance reduction, the increased complexity of computing a daily hedge, the illiquidity of this market and the higher trading costs suggest against using a daily hedge, except if we are strongly interested in reducing the probability of a large occasional fall in the CDS portfolio.

\subsection{Hedging portfolios of different size}

In this section we examine how the efficiency of the least-squares hedge changes with the number of firms in the portfolio using the sample of North American firms. Hedging results for small portfolios will depend on the nature of the firms included in the portfolio, so we have run two different exercises.

\footnotetext{
${ }^{12} \mathrm{As}$ it can be observed in graphs similar to those presented for the least-squares hedge, which we do not include in the paper.
} 
First, we consider portfolios with 5, 25, 50, 100, 225 and 360 firms, with portfolio components being selected starting from the most idiosyncratic firms. Second, we perform the analysis starting from the least idiosyncratic firms. Clearly, the hedge should yield better results for small portfolios in the last case.

To estimate idiosyncratic components, we use as reference the first principal component of the weekly changes in CDS spreads for the whole sample of North American firms, as an indicator of the aggregate risk in the credit market (as is done in Longstaff et al. (2011)). The correlation between the weekly changes in CDS spread and the principal component is used to rank firms, a low correlation indicating the more idiosyncratic ones. ${ }^{13}$ Table 7 shows the results when we start bulding portfolios including the most idiosyncratic firms. For each portfolio, we show the percent reduction in portfolio mark-to-market variance. Throughout each period, we used 52-week windows to estimate a hedge ratio. The least squares hedge ratio is estimated each week and the hedge is adjusted accordingly. As in previous sections, we consider the full sample as well as the same three subperiods: pre-crisis, up to the end of 2007, crisis: 2008 and 2009, and post-crisis: 2010, 2011 and 2012. Hedging results were again generally much better before and after the crisis that during the financial crisis. The hedge does not achieve any improvement for small portfolios, and it starts being effective when we include the 50 most idiosyncratic firms, corresponding to an approximate Herfindahl index of $2 \%$. For that portfolio, the hedge achieves a reduction in MtM variance above $30 \%$ in the more tranquil periods. Hedging results improve with the number of CDS contracts in the portfolio, although there seems to be no further gain once we include 225 firms. For the largest portfolio of 360 firms, the hedge reduces mark-to-market variance by $60 \%$. When we start building portfolios with the least idiosyncratic firms, the percent reduction in volatility is essentially independent from the number of firms, and the table shows that even for the small portfolio of 5 firms the percent reduction in mark-to-market variance is already similar to the one achieved with the large portfolios made up of the most idyiosincratic CDS contracts. The degree of market concentration is not important in these portfolios. Figure 11 shows the reduction in mark-to-market variance as a function of the number of firms as we include in the portfolio either the more idyosincratic or the less idiosyncratic CDS contracts. If we constructed portfolios choosing at random from our sample of 260 North American firms, the reduction in volatility would fall at some point between these two lines. ${ }^{14}$

\section{(INSERT HERE TABLE 7)}

\section{(INSERT HERE FIGURE 11)}

Table 8 shows the probability that each portfolio may suffer a loss above one or two standard deviations of the mark-to-market of the unhedged portfolio. The incidence of high losses prior to the crisis

\footnotetext{
${ }^{13}$ Chamizo and Novales (2016)use this principal component in a regression model to obtain a decomposition of credit risk into systematic, sectorial and idyosincratic components.

${ }^{14}$ Even a uniform, purely random selection of firms might translate into an interesting probability distribution on variance reduction.
} 
is eliminated by the hedge in portfolios of 50 or more names. During the crisis the frequency of losses above one standard deviation seems to be increasing with the portfolio size, but the hedge reduced significantly such incidence. After the crisis the incidence of large losses was lower than during the crisis, and the hedge was again successful in reducing their number.

(INSERT HERE TABLE 8)

\section{Determinants of hedging efficiency}

As a summary of the results in previous sections, the wedge between the 20-week volatility of the unhedged and hedged equally-weighted portfolio of the 360 US CDS in our sample in Figure 12 signals the efficiency of the hedge. The reduction in volatility became less important when the crisis started, until the end of 2008, after the Lehmann Brothers bankruptcy. It improved from that point until October 2010, to decrease sharply again up to a minimum close to zero on May-June 2011, the time of the EU bailout to Portugal and the downgrade of S\&P to Greece. The reduction in variance quickly recovered from there up to a level of around $50 \%$.

\section{(INSERT HERE FIGURE 12)}

Thus, the hedging efficiency of the credit portfolio can be seen to experience significant change over time that could be related to some of the variables more relevant for the works of the financial markets and hence for the expectations of economic agents, conditioning their decisiones and the evolution of the economy. It seems natural to consider short- and long-term interest rates, volatility indicators as well as some measure of liquidity. As portfolio characteristics we include the current volatility and the portfolio size. Pooling the weekly data for the six portfolios made up by a different number of North American firms that were considered in the previous section, we estimated the regression model,

$$
\begin{aligned}
& \text { Reduc }_{t}=0.0010+\underset{(12.9)}{18.26 \text { Volat }_{t i}}+\underset{(17.9)}{9.71} \mathrm{L3m}_{t}-\underset{(7.4)}{3.50 S w 10_{t}}-\underset{(8.2)}{10.31 \mathrm{Dliq}_{t}-} \\
& -\underset{(3.3)}{019} \mathrm{VIX}_{t}+\underset{(4.1)}{0.71 \text { VlE }_{t}}+\underset{(41.2)}{0.11} \text { Size }_{i t}+\underset{(13.3)}{10.9 \text { Crisis }_{t}}+\hat{u}_{t}, \operatorname{adj} R^{2}=0.74
\end{aligned}
$$

where Reduc is the percent reduction in volatility, as measured by the standard deviation of weekly changes in the portfolio MtM, Volat is the current level of volatility of the unhedged portfolio, in both cases estimated with a 52-week window, L3m denotes the 3-month Libor rate, Sw10 is the 10-year swap rate in USD, Dliq is the absolute difference between the 3-month Libor and the USD Overnight Indexed Swap (OIS) 3-month rate as a proxy for liquidity risk in the US, VIX denotes the US index of implied volatility of stock market options, and VolEx is the volatility of the 3-month forward Euro/USD exchange. Size is the number of firms in the portfolio and Crisis is a dummy variable taking a value of 
1 during the crisis period, and zero otherwise. ${ }^{15}$ The regression achieves an adjusted R2 of 0.74 . The percent reduction in volatility increases with the number of firms included in the portfolio, an increase in 50 firms reducing volatiliy by 5 additional percentage points. The reduction in volatility is also 11 percentage points larger in tranquil periods. The percent reduction is larger when portfolio volatility is high and also when short term interest rates or exchange rate volatility are high. An increase in VIX, the 10-year swap rate or the level of liquidity risk, ceteris paribus, tends to decrease the percent reduction in volatility achieved by the hedge. However, it is not advisable to interpret the estimated coefficients individually, since the Libor rate has a linear correlation of 0.87 with the Swap rate, and the exchange rate volatility, the VIX index, and the liquidity risk indicator are also correlated among them. Thus, collinearity leads to lack of precision in individual coefficient estimates, even if allowing for a precise estimation of the global explanatory power of the regression. ${ }^{16}$

\section{Risk analysis with corporate bond data}

Througout the financial crisis, banks often invested in corporate bonds to get a better return in their portfolios. However the market for corporate bonds is well known to be rather illiquid, and we examine in this section whether a credit index could be used to hedge such a portfolio. Another motivation for this analysis comes from the need to cover the risk involved in loans, credit lines, and bank guarantees, for which there natural hedging instruments do not exist. We take bond data for the June 2006-June 2018 period from firms currently included in the MARKIT CDX.NA.IG.31 12/23 index. ${ }^{17}$ We also want to use this sample to evaluate the more recent level of efficiency of the hedge provided by credit indices for credit portfolios. Unfortunately, the use of a longer 2006-2018 sample drastically reduces the number of firms satisfying our filters. All data are in USD. At any given point in time we chose for each firm the bond closest to 5-year maturity, since we want to compare the results with those obtained from 5-year CDS spreads. We excluded bonds for which we did not have data at least $90 \%$ of the weeks over the sample period, as well as bonds with maturity below one year. We selected senior unsecured bullet bonds to avoid the price of the bond being affected by the existence of a callable option, and we only considered issues over 500 million USD to have some guarantee of liquidity. These two filters help us to interpret the bond spread as reflecting credit quality, although there will still be some basis risk remaining. We started with an initial group of 125 firms, those for which we had historical prices in either BGN or CBBT, and 1043 bonds. After application of the filters we ended up with a portfolio of 45 Investment Grade bonds from the US. With the filtered data we obtained the asset swap spread, calculating the weekly average of the available daily data over any given week. Finally, we adjusted the asset swap by the spread between the swap curve and the 5-year Treasury, so

\footnotetext{
${ }^{15}$ A higher value of Dliq would indicate high systemic risk and low liquidity. Before the financial crisis, this variable was close to zero.

${ }^{16}$ Collinearity also inflates the variance of estimates, so that having statistically significant coefficients in the presence of high collinearity is particularly interesting.

${ }^{17}$ Chamizo et al. (2019) use this same data set to compare the value at risk estimates of both portfolios.
} 
that the spread is referred to the risk-free curve. We estimated missing weekly spread data by taking the previous observation adjusted by the average spread change observed that week for the firms in the portfolio. We follow the framework described in Section 3 to compute hedging efficiency, using as credit index the CDX North American Investment Grade.

Figure 13 shows that the pattern of volatility was very similar in both markets. ${ }^{18}$ Volatility sharply increased at the end of March 2008, well before the first evidence of the financial crisis was noticed, and started to decrease in March 2009. Volatility increased again in February 2011 because of evidence on the European sovereign debt crisis, coming back to more normal values one year later, in February 2012. Finally, volatility increased again in July 2015, reaching their peak in February 2016 and decreasing afterwards, as a sign of the increased risk brought about by a global stock market selloff due to several factors: the Chinese stock market turbulence, in which the SSE Composite Index fell $43 \%$ in just over 2 months between June 2015 and August 2015, culminating in the devaluation of the yuan, a fall in petroleum prices, the Greek debt default in June 2015, the effects of the end of quantitative easing in the United States in October 2014, a sharp rise in bond yields in early 2016, and finally, in June 2016, the United Kingdom European Union membership referendum, 2016, in which Brexit was voted upon.

\section{(INSERT HERE FIGURE 13 )}

Table 9 summarizes the hedging results. We can see that the volatility of the unhedged corporate and CDS portfolios was quite similar, with the exception of the pre-crisis period, when the variance of the CDS portfolio was more than $20 \%$ above the volatility of the bond portfolio. The hedge is quite successful for the credit portfolio, with an average variance reduction of $60 \%$, which becomes significantly higher during the more tranquil periods. The hedge for the credit portfolio was less efficient during the financial crisis, with a decrease in variance of $55 \%$, versus a reduction of $71 \%$ before and after the crisis. The hedge would have also been successful for the bond portfolio, with a $40 \%$ reduction in variance, a similar level over the three periods considered.

\section{(INSERT HERE TABLE 9 )}

\section{Conclusions and open questions}

To analyze the possibilities of hedging CDS portfolios with credit indices we have estimated the level of market risk that remains after such a hedge. We have considered regional (European, North American, Japanese) credit portfolios as well as a global portfolio, and we have examined the precrisis, crisis and post-crisis periods separately. We have also examined the efficiency of the hedge for sectorial credit portfolios in Europe and North America. We have evaluated the efficiency of a least-

\footnotetext{
${ }^{18}$ Estimated as the standard deviation of returns in a rolling window of 52 weeks
} 
squares hedging strategy based on weekly observations, under alternative hedging strategies.

A single-index least-squares hedge achieves a significant reduction in P\&L variance. The probability of having an extreme loss is also sharply reduced by the hedge. However, significant market risk remains even in well-diversified portfolios, with more than seven hundred CDS contracts, showing that their idiosyncratic components do not compensate with each other. Results are similar for the different regions as well as for the global portfolio, although the hedge seems to be more effective in Europe and Japan than in North America. There are noticeable differences in the efficiency of the hedge across sectors both in Europe and North America, an important result regarding asset allocation decisions. Hedging efficiency seems to be closely related to the correlation between a given sector and the credit index, moreso than to the volatility of the sector relative to the hedging credit index, or to the size of the hedge ratio. The hedge was somewhat less effective during the financial crisis due to decreased correlations between single names and credit indices, although it still achieved a significant reduction in risk. Using a strategy that takes into account the quality of the credit counterpart improves the effectiveness of the hedge, although it requires using less liquid credit indices, with higher transaction costs. Dynamic Conditional Correlation (DCC) estimates of the hedge ratio might be optimal in a high volatility market, while performing similarly to the least-squares (least squares) hedge over the course of an economic cycle. DCC hedge estimates are however more volatile, leading to higher entry and exit costs to adjust the hedge continuously.

The hedge efficiency increases with the number of firms in the portfolio, although the level of efficiency depends on the nature of the firms included in the portfolio. If we include the most idiosyncratic firms, we may need more than 50 names to achieve some significant reduction in P\&L variance. On the other hand, if the portfolio includes the least idiosyncratic firms, we achieve significant efficiency even with small portfolios. Thus, our analysis has clear implications for credit risk management, since the sectorial strategy should depend on the risk decomposition of firms in a given sector. Indeed, it would seem appropriate to impose a maximum exposure to sectors where firms have a large systematic risk component while being relatively flexible about the distribution inside the sector, since a small idiosyncratic component would not allow us to extract the benefits of diversification by increasing the number of firms in the portfolio. On the contrary, in a sector where firms have large idiosyncratic risk component, we should avoid having a high name concentration, since a better diversification would reduce the total risk of the portfolio.

In addition to the effect of the size of the portfolio, the percent reduction in the variance of the portfolio achieved by the hedge is higher when portfolio volatility is high and also when short term interest rates or exchange rate volatility are high. An increase in VIX, in the 10-year swap rate or in liquidity risk, ceteris paribus, tends to decrease the percent reduction in volatility achieved by the hedge.

A relevant implication from our analysis is that some basis points should be charged to the price 
of financial credit products in terms of unhedgeable risk. A natural beginning would be to estimate the expected loss in basis points as a function of a proxy portfolio, adjusted by maturity, to be added as an extra charge to the price of derivatives. From the point of view of regulators, we could think of using a historical percentile of a P\&L distribution, as estimated in this paper, as lower bound for the level of market risk that should be added in terms of capital and monitor that risk among the financial institutions in order to prevent future problems.

Jump-to-Default risk cannot be ignored as delta hedging is a partial hedge and its effectiveness is predicated on a continuous adjustment of the hedge ratio. Therefore, if a single firm jumped to default, we would not be able to adjust the hedge ratio appropriately, and the defaulted credit exposure would not be fully covered, resulting in a loss. Thus, name concentration can be partially, but not fully eliminated. In general, it will be easier for portfolio management and hedging to reduce sector concentration than name concentration, unless CDS have been issued for that firm. The possibility of calibrating a jump model to evaluate the effectiveness of the credit index hedge in case of Jump-toDefault of a firm not included in the index remains as an open question. It would also be interesting to carry out the analysis in this paper under alternative assumptions, like non-zero transaction costs, stochastic exposures, or using an alternative strategy involving the simultaneous use of several credit indices. Another alternative would consider hedging the credit portfolio with credit and equity indices, since the latter are highly liquid assets and show high correlation with credit indices, suggesting that such a strategy might reduce the level of market risk.

\section{References}

BCBS, 2006. Studies on credit risk concentration. BCBS Working Paper 15.

BCBS, 2011. Basel III: A global regulatory framework for more resilient banks and banking systems. Basel Committee on Banking Supervision, Basel.

BCBS, 2012. Basel III counterparty credit risk and exposures to central counterparties - Frequently asked questions. Basel Committee on Banking Supervision, Basel.

BCBS, 2015. Statistical release OTC derivatives statistics at end-December 2014. Basel Committee on Banking Supervision, Basel.

Chamizo, Á., Fonollosa, A., Novales, A., 2019. Forward-looking asset correlations in the estimation of economic capital. Journal of International Financial Markets, Institutions and Money 61, 264-288.

Chamizo, A., Novales, A., 2016. Credit risk decomposition for asset allocation. Journal of Financial Transformation (43), 117-123.

Duffie, D., Singleton, K. J., 1999. Modeling term structures of defaultable bonds. Review of Financial studies 12 (4), 687-720.

Engle, R., 2002. Dynamic conditional correlation: A simple class of multivariate generalized autoregressive conditional heteroskedasticity models. Journal of Business \& Economic Statistics 20 (3), $339-350$. 
Hull, J. C., 2012. Risk management and financial institutions. Third edition. Jonh Wiley \& Sons.

Leung, S.-l., Banks, M. B., Saary-Littman, J., 2017. Principles and practices.the expanding role of credit portfolio management within the firm.

Longerstaey, J., Spencer, M., 1996. Riskmetrics technical document. Morgan Guaranty Trust Company of New York: New York.

Longstaff, F. A., Pan, J., Pedersen, L. H., Singleton, K. J., 2011. How sovereign is sovereign credit risk? American Economic Journal: Macroeconomics 3 (2), 75-103.

Markit, 2009. The CDS Big Bang: Understanding the changes to the global CDS contract and North American conventions.

White, R., 2013. The pricing and risk management of credit default swaps, with a focus on the isda model. OpenGamma Quantitative Research (16). 


\section{Appendix}

Table 1: Distribution of CDS contracts by industry and region

\begin{tabular}{|c|c|c|c|c|}
\hline Industry/Region & Europe & Japan & North America & Total \\
\hline \hline Basic materials & 17 & 13 & 33 & 63 \\
\hline Consumer goods & 33 & 23 & 54 & 110 \\
\hline Consumer services & 35 & 16 & 52 & 103 \\
\hline Energy & 6 & 3 & 33 & 42 \\
\hline Financials & 69 & 17 & 61 & 147 \\
\hline Health care & 4 & 0 & 24 & 28 \\
\hline Industrials & 30 & 24 & 46 & 100 \\
\hline Technology & 5 & 8 & 16 & 29 \\
\hline Telecommunication services & 20 & 3 & 14 & 37 \\
\hline Utilities & 27 & 9 & 27 & 63 \\
\hline Total & 246 & 116 & 360 & 722 \\
\hline
\end{tabular}

Notes: The table shows the number of CDS contracts in our sample, by sector and region.

Table 2: Hedge ratio decompositions: European portfolio

\begin{tabular}{|c|c|c|c|c|c|c|c|c|c|c|c|c|}
\hline \multirow{2}{*}{ Sector } & \multicolumn{3}{|c|}{ Full sample } & \multicolumn{3}{|c|}{ Pre-crisis } & \multicolumn{3}{|c|}{ Crisis } & \multicolumn{3}{|c|}{ Post-crisis } \\
\hline & H.R. & Rho & R.Vol. & H.R. & Rho & R.Vol. & H.R. & Rho & R.Vol. & H.R. & Rho & R.Vol. \\
\hline Basic materials & 1.36 & 0.67 & 2.12 & 1.06 & 0.72 & 1.54 & 1.70 & 0.68 & 2.59 & 1.35 & 0.69 & 2.10 \\
\hline Consumer goods & 0.55 & 0.70 & 0.92 & 0.57 & 0.66 & 0.85 & 0.63 & 0.70 & 1.01 & 0.34 & 0.72 & 0.57 \\
\hline Consumer services & 0.66 & 0.68 & 1.27 & 0.77 & 0.64 & 1.47 & 0.77 & 0.63 & 1.37 & 0.55 & 0.72 & 0.83 \\
\hline Energy & 0.42 & 0.59 & 0.65 & 0.15 & 0.47 & 0.31 & 0.35 & 0.61 & 0.59 & 0.42 & 0.66 & 0.60 \\
\hline Financials & 0.97 & 0.66 & 1.47 & 0.45 & 0.54 & 0.76 & 0.96 & 0.66 & 1.52 & 1.09 & 0.72 & 1.43 \\
\hline Health care & 0.27 & 0.65 & 0.41 & 0.20 & 0.55 & 0.36 & 0.38 & 0.71 & 0.53 & 0.19 & 0.66 & 0.30 \\
\hline Industrials & 0.92 & 0.69 & 1.29 & 0.73 & 0.67 & 1.09 & 0.98 & 0.67 & 1.53 & 0.73 & 0.73 & 0.97 \\
\hline Technology & 0.65 & 0.62 & 1.26 & 0.62 & 0.58 & 1.34 & 0.74 & 0.61 & 1.18 & 0.64 & 0.63 & 0.93 \\
\hline Telecommunication services & 0.64 & 0.70 & 0.92 & 0.72 & 0.66 & 1.26 & 0.67 & 0.71 & 0.93 & 0.55 & 0.76 & 0.73 \\
\hline Utilities & 0.44 & 0.65 & 0.60 & 0.42 & 0.60 & 0.73 & 0.43 & 0.63 & 0.63 & 0.35 & 0.68 & 0.53 \\
\hline Correlations with hedge ratio & & 0.33 & 0.96 & & 0.90 & 0.94 & & 0.15 & 0.99 & & 0.20 & 0.99 \\
\hline Correlation(Rho, R.Vol) & & & 0.25 & & & 0.77 & & & 0.08 & & & 0.14 \\
\hline Correlations with hedging efficiency & 0.05 & 0.68 & -0.05 & 0.25 & 0.58 & 0.08 & 0.02 & 0.95 & -0.03 & 0.07 & 0.83 & 0.05 \\
\hline
\end{tabular}

Notes: H.R.= hedge ratio, Rho = correlation, R.Vol = volatility of unhedged credit portfolio relative to the credit index. The table shows hedge ratios, correlations betweens ectors and credit index, and sectorial volatility relative to the credit index. The last three rows show: correlations of Rho and R.Vol with the hedge ratio, Correlation between Rho and R.Vol., and correlations of the three variables with hedging efficiency in Table 4 . 
Table 3: Hedge ratio decompositions: North American portfolio

\begin{tabular}{|c|c|c|c|c|c|c|c|c|c|c|c|c|}
\hline \multirow{2}{*}{ Sector } & \multicolumn{3}{|c|}{ Full sample } & \multicolumn{3}{|c|}{ Pre-crisis } & \multicolumn{3}{|c|}{ Crisis } & \multicolumn{3}{|c|}{ Post-crisis } \\
\hline & H.R. & Rho & R.Vol. & H.R. & Rho & R.Vol. & H.R. & Rho & R.Vol. & H.R. & Rho & R.Vol. \\
\hline Basic materials & 0.61 & 0.59 & 1.31 & 0.38 & 0.49 & 0.84 & 0.69 & 0.61 & 1.16 & 0.71 & 0.59 & 1.45 \\
\hline Consumer goods & 0.99 & 0.58 & 1.62 & 0.92 & 0.56 & 1.49 & 0.73 & 0.60 & 1.29 & 0.88 & 0.60 & 1.61 \\
\hline Consumer services & 0.81 & 0.62 & 1.48 & 0.67 & 0.53 & 1.33 & 0.74 & 0.64 & 1.16 & 0.85 & 0.62 & 1.40 \\
\hline Energy & 0.46 & 0.54 & 1.16 & 0.30 & 0.50 & 0.73 & 0.50 & 0.52 & 1.23 & 0.64 & 0.61 & 1.39 \\
\hline Financials & 1.02 & 0.60 & 1.74 & 0.42 & 0.54 & 0.87 & 1.05 & 0.57 & 1.78 & 1.23 & 0.79 & 1.67 \\
\hline Health care & 0.29 & 0.48 & 0.84 & 0.24 & 0.36 & 0.93 & 0.29 & 0.50 & 0.83 & 0.31 & 0.54 & 0.74 \\
\hline Industrials & 0.64 & 0.56 & 1.30 & 0.41 & 0.44 & 1.18 & 0.54 & 0.58 & 1.08 & 0.51 & 0.63 & 1.18 \\
\hline Technology & 0.61 & 0.55 & 1.14 & 0.24 & 0.38 & 1.40 & 0.46 & 0.56 & 0.77 & 1.14 & 0.62 & 1.86 \\
\hline Telecommunication services & 0.48 & 0.49 & 1.27 & 0.60 & 0.47 & 1.86 & 0.42 & 0.46 & 0.94 & 0.29 & 0.58 & 0.78 \\
\hline Utilities & 0.46 & 0.50 & 0.95 & 0.43 & 0.51 & 0.79 & 0.48 & 0.47 & 1.05 & 0.55 & 0.53 & 0.92 \\
\hline Correlations with hedge ratio & & 0.83 & 0.95 & & 0.68 & 0.56 & & 0.62 & 0.91 & & 0.74 & 0.93 \\
\hline Correlation(Rho, R.Vol) & & & 0.83 & & & -0.05 & & & 0.35 & & & 0.72 \\
\hline Correlations with hedging efficiency & 0.63 & 0.83 & 0.54 & 0.10 & 0.61 & -0.36 & 0.74 & 0.86 & 0.49 & 0.68 & 0.81 & 0.58 \\
\hline
\end{tabular}

Notes: H.R.= hedge ratio, Rho = correlation, $\mathrm{R} . \mathrm{Vol}=$ volatility of unhedged credit portfolio relative to the credit index. The table shows hedge ratios, correlations between sectors and credit index, and sectorial volatility relative to the credit index. The last three rows show: correlations of Rho and R.Vol with the hedge ratio, Correlation between Rho and R.Vol., and correlations of the three variables with hedging efficiency in Table 4 .

Table 4: Hedging efficiency: Sectorial portfolios

\begin{tabular}{|c|c|c|c|c|c|c|c|c|}
\hline & \multicolumn{4}{|c|}{ Europe } & \multicolumn{4}{|c|}{ North America } \\
\hline & Full sample & Pre-crisis & Crisis & Post-crisis & Full sample & Pre-crisis & Crisis & Post-crisis \\
\hline Basic materials & $49 \%$ & $70 \%$ & $39 \%$ & $54 \%$ & $32 \%$ & $49 \%$ & $28 \%$ & $33 \%$ \\
\hline Consumer services & $43 \%$ & $66 \%$ & $36 \%$ & $58 \%$ & $37 \%$ & $51 \%$ & $33 \%$ & $41 \%$ \\
\hline Energy & $41 \%$ & $54 \%$ & $33 \%$ & $50 \%$ & $25 \%$ & $42 \%$ & $21 \%$ & $41 \%$ \\
\hline Health care & $53 \%$ & $75 \%$ & $48 \%$ & $53 \%$ & $27 \%$ & $39 \%$ & $14 \%$ & $34 \%$ \\
\hline Industrials & $47 \%$ & $71 \%$ & $41 \%$ & $60 \%$ & $34 \%$ & $43 \%$ & $28 \%$ & $39 \%$ \\
\hline Technology & $36 \%$ & $57 \%$ & $32 \%$ & $33 \%$ & $29 \%$ & $43 \%$ & $25 \%$ & $35 \%$ \\
\hline Telecommunication services & $53 \%$ & $78 \%$ & $43 \%$ & $60 \%$ & $22 \%$ & $30 \%$ & $18 \%$ & $27 \%$ \\
\hline Utilities & $39 \%$ & $70 \%$ & $33 \%$ & $52 \%$ & $25 \%$ & $40 \%$ & $23 \%$ & $32 \%$ \\
\hline
\end{tabular}

Notes: Percent reduction in mark-to-market variance when hedging sectorial portfolios with a credit index (iTraxx for Europe, CDX for the US) 
Table 5: Hedging efficiency: Regional portfolios

\begin{tabular}{|c|c|c|c|c|}
\hline & Europe & North America & Japan & Global \\
\hline Full sample & & & & \\
\hline One-index: & $81 \%$ & $60 \%$ & $60 \%$ & $71 \%$ \\
\hline Two-index (High vol/High yield) & $85 \%$ & $72 \%$ & $60 \%$ & $79 \%$ \\
\hline Two-index (Crossover) & $83 \%$ & $72 \%$ & $60 \%$ & $78 \%$ \\
\hline DCC hedge & $81 \%$ & $60 \%$ & $59 \%$ & $71 \%$ \\
\hline Daily hedge & $71 \%$ & $42 \%$ & $42 \%$ & $63 \%$ \\
\hline pre-crisis & & & & \\
\hline One-index & $83 \%$ & $76 \%$ & $63 \%$ & $82 \%$ \\
\hline Two-index (High vol/High yield) & $89 \%$ & $73 \%$ & $63 \%$ & $83 \%$ \\
\hline Two-index (Crossover) & $89 \%$ & $73 \%$ & $63 \%$ & $82 \%$ \\
\hline DCC hedge & $84 \%$ & $76 \%$ & $62 \%$ & $83 \%$ \\
\hline Daily hedge & $81 \%$ & $28 \%$ & $50 \%$ & $55 \%$ \\
\hline crisis & & & & \\
\hline One-index & $74 \%$ & $55 \%$ & $60 \%$ & $67 \%$ \\
\hline Two-index (High vol/High yield) & $79 \%$ & $67 \%$ & $60 \%$ & $74 \%$ \\
\hline Two-index (Crossover) & $76 \%$ & $67 \%$ & $61 \%$ & $74 \%$ \\
\hline DCC hedge & $71 \%$ & $56 \%$ & $59 \%$ & $66 \%$ \\
\hline Daily hedge & $65 \%$ & $33 \%$ & $42 \%$ & $57 \%$ \\
\hline post-crisis & & & & \\
\hline One-index & $91 \%$ & $70 \%$ & $59 \%$ & $80 \%$ \\
\hline Two-index (High vol/High yield) & $93 \%$ & $85 \%$ & $59 \%$ & $89 \%$ \\
\hline DCC hedge & $92 \%$ & $85 \%$ & $59 \%$ & $89 \%$ \\
\hline Daily hedge & $91 \%$ & $70 \%$ & $58 \%$ & $81 \%$ \\
\hline & $76 \%$ & $59 \%$ & $41 \%$ & $71 \%$ \\
\hline
\end{tabular}

Notes: The table shows the percent reduction in the variance of weekly changes in the MtM of regional portfolios achieved by the hedge. 'One-index' refers to the hedge obtained from a single index. 'Two-index' refers to the hedge based on two CDS indices as described in the paper. 'DCC hedge' refers to the hedge with the DCC-EWMA model. 'Daily data' refers to results obtained using daily data (Unhedged/Hedged portfolios). The hedge is estimated each week using a 52-week window. 
Table 6: Probability of a large weekly fall in MtM

\begin{tabular}{|c|c|c|c|c|c|c|c|c|}
\hline & \multicolumn{2}{|c|}{ Europe } & \multicolumn{2}{|c|}{ North America } & \multicolumn{2}{|c|}{ Japan } & \multicolumn{2}{|c|}{ Global } \\
\hline Full sample & $1 \sigma$ & $2 \sigma$ & $1 \sigma$ & $2 \sigma$ & $1 \sigma$ & $2 \sigma$ & $1 \sigma$ & $2 \sigma$ \\
\hline Unhedged & $15.8 \%$ & $5.8 \%$ & $13.2 \%$ & $4.2 \%$ & $9.0 \%$ & $3.2 \%$ & $15.1 \%$ & $4.2 \%$ \\
\hline One-index & $3.2 \%$ & $0.3 \%$ & $5.5 \%$ & $1.9 \%$ & $7.1 \%$ & $1.6 \%$ & $4.5 \%$ & $1.0 \%$ \\
\hline Two-index (High vol/High yield) & $2.9 \%$ & $0.6 \%$ & $4.2 \%$ & $1.3 \%$ & $7.1 \%$ & $1.6 \%$ & $3.9 \%$ & $0.3 \%$ \\
\hline Two-index (Crossover) & $2.9 \%$ & $0.6 \%$ & $4.2 \%$ & $1.3 \%$ & $7.1 \%$ & $1.6 \%$ & $3.9 \%$ & $0.3 \%$ \\
\hline DCC hedge & $2.9 \%$ & $0.0 \%$ & $5.8 \%$ & $1.6 \%$ & $6.8 \%$ & $1.0 \%$ & $4.8 \%$ & $1.0 \%$ \\
\hline Daily data (Unhedged) & $4.8 \%$ & $0.6 \%$ & $5.8 \%$ & $0.6 \%$ & $3.2 \%$ & $1.3 \%$ & $4.8 \%$ & $0.6 \%$ \\
\hline Daily data (Hedged) & $1.9 \%$ & $0.0 \%$ & $6.1 \%$ & $1.9 \%$ & $1.3 \%$ & $0.6 \%$ & $2.6 \%$ & $0.6 \%$ \\
\hline \multicolumn{9}{|l|}{ pre-crisis } \\
\hline Unhedged & $6.0 \%$ & $0.0 \%$ & $6.0 \%$ & $0.0 \%$ & $0.0 \%$ & $0.0 \%$ & $6.0 \%$ & $0.0 \%$ \\
\hline One-index & $0.0 \%$ & $0.0 \%$ & $0.0 \%$ & $0.0 \%$ & $0.0 \%$ & $0.0 \%$ & $0.0 \%$ & $0.0 \%$ \\
\hline Two-index (High vol/High yield) & $0.0 \%$ & $0.0 \%$ & $0.0 \%$ & $0.0 \%$ & $0.0 \%$ & $0.0 \%$ & $0.0 \%$ & $0.0 \%$ \\
\hline Two-index (Crossover) & $0.0 \%$ & $0.0 \%$ & $0.0 \%$ & $0.0 \%$ & $0.0 \%$ & $0.0 \%$ & $0.0 \%$ & $0.0 \%$ \\
\hline DCC hedge & $0.0 \%$ & $0.0 \%$ & $0.0 \%$ & $0.0 \%$ & $0.0 \%$ & $0.0 \%$ & $0.0 \%$ & $0.0 \%$ \\
\hline Daily data (Unhedged) & $0.0 \%$ & $0.0 \%$ & $2.0 \%$ & $0.0 \%$ & $0.0 \%$ & $0.0 \%$ & $0.0 \%$ & $0.0 \%$ \\
\hline Daily data (Hedged) & $0.0 \%$ & $0.0 \%$ & $4.0 \%$ & $0.0 \%$ & $0.0 \%$ & $0.0 \%$ & $0.0 \%$ & $0.0 \%$ \\
\hline \multicolumn{9}{|l|}{ crisis } \\
\hline Unhedged & $21,2 \%$ & $7.7 \%$ & $23.1 \%$ & $7.7 \%$ & $19.2 \%$ & $6.7 \%$ & $24.0 \%$ & $7.7 \%$ \\
\hline One-index & $6.7 \%$ & $1.0 \%$ & $11.5 \%$ & $4.8 \%$ & $14.4 \%$ & $4.8 \%$ & $10.6 \%$ & $2.9 \%$ \\
\hline Two-index (High vol/High yield) & $6.7 \%$ & $0.0 \%$ & $9.6 \%$ & $3.8 \%$ & $14.4 \%$ & $4.8 \%$ & $9.6 \%$ & $1.0 \%$ \\
\hline Two-index (Crossover) & $7.7 \%$ & $1.9 \%$ & $9.6 \%$ & $3.8 \%$ & $14.4 \%$ & 4.8 & $10.6 \%$ & 1.0 \\
\hline DCC hedge & $5.8 \%$ & $0.0 \%$ & $11.5 \%$ & $4.8 \%$ & $13.5 \%$ & $2.9 \%$ & $9.6 \%$ & $2.9 \%$ \\
\hline Daily data(Unhedged) & $1.9 \%$ & $1.0 \%$ & $3.8 \%$ & $0.0 \%$ & $1.9 \%$ & $0.0 \%$ & $3.8 \%$ & $1.3 \%$ \\
\hline Daily data (Hedged) & $0.0 \%$ & $0.0 \%$ & $2.9 \%$ & $1.9 \%$ & $0.1 \%$ & $0.0 \%$ & $1.9 \%$ & $0.6 \%$ \\
\hline \multicolumn{9}{|l|}{ post-crisis } \\
\hline Unhedged & $15.3 \%$ & $6.4 \%$ & $8.9 \%$ & $3.2 \%$ & $5.1 \%$ & $1.9 \%$ & $12.1 \%$ & $3.2 \%$ \\
\hline One-index & $1.9 \%$ & $0.0 \%$ & $3.2 \%$ & $0.6 \%$ & $4.5 \%$ & $0.0 \%$ & $1.9 \%$ & $0.0 \%$ \\
\hline Two-index (High vol/High yield) & $0.0 \%$ & $0.0 \%$ & $1.9 \%$ & $0.0 \%$ & $4.5 \%$ & $0.0 \%$ & $0.0 \%$ & $0.0 \%$ \\
\hline Two-index (Crossover) & $0.6 \%$ & $0.0 \%$ & $1.9 \%$ & $0.0 \%$ & $4.5 \%$ & $0.0 \%$ & $0.6 \%$ & $0.0 \%$ \\
\hline DCC hedge & $1.9 \%$ & $0.0 \%$ & $3.8 \%$ & $0.0 \%$ & $4.5 \%$ & $0.0 \%$ & $3.2 \%$ & $3.2 \%$ \\
\hline Daily data (Unhedged) & $8.3 \%$ & $0.6 \%$ & $8.3 \%$ & $1.3 \%$ & $5.1 \%$ & $2.5 \%$ & $7.0 \%$ & $1.3 \%$ \\
\hline Daily data (Hedged) & $3.8 \%$ & $0.0 \%$ & $8.9 \%$ & $2.5 \%$ & $2.5 \%$ & $1.3 \%$ & $3.8 \%$ & $0.6 \%$ \\
\hline
\end{tabular}

Notes: The table shows the probability of a weekly fall larger than one or two standard deviations of the unhedged portfolio. 'One-index' refers to the hedge obtained from a single index. 'Two-index' refers to the hedge based on two CDS indices as described in the paper.'DCC hedge' refers to the hedge with the DCC-EWMA model. 'Daily data' refers to results obtained using daily data (Unhedged/Hedged portfolios). The hedge is estimated each week using a 52-week window.

Table 7: Percent reduction in the variance of weekly MtM changes: North American firms

\begin{tabular}{|c|c|c|c|c|c|c|c|}
\hline & \multicolumn{6}{|c|}{ More idiosyncratic firms } & Less idiosyncratic firms \\
\hline Number of firms & 5 & 25 & 50 & 100 & 225 & 360 & 5 \\
\hline Full sample & $-6 \%$ & $-4 \%$ & $11 \%$ & $46 \%$ & $56 \%$ & $60 \%$ & $61 \%$ \\
\hline pre-crisis & $-7 \%$ & $-58 \%$ & $37 \%$ & $83 \%$ & $79 \%$ & $77 \%$ & $64 \%$ \\
\hline crisis & $-9 \%$ & $2 \%$ & $8 \%$ & $41 \%$ & $52 \%$ & $57 \%$ & $60 \%$ \\
\hline post-crisis & $-2 \%$ & $10 \%$ & $34 \%$ & $58 \%$ & $66 \%$ & $70 \%$ & $73 \%$ \\
\hline
\end{tabular}

Notes: The table shows the percent reduction in variance of weekly MtM changes of each portfolio as a consequence of hedging with the CDX index, when we consider the more idiosyncratic firms. The last column corresponds to the portfolio of the 5 less idiosyncratic firms. The hedge is estimated each week using a 52-week window. 
Table 8: Probabilities of a large weekly change in MtM for portfolios of different size

\begin{tabular}{|c|c|c|c|c|c|c|}
\hline Number of firms & 5 & 25 & 50 & 100 & 225 & 360 \\
\hline \hline \multicolumn{7}{|c|}{ Whole sample } \\
\hline Unhedged $(1 \sigma)$ & $9 \%$ & $10 \%$ & $6 \%$ & $14 \%$ & $14 \%$ & $14 \%$ \\
\hline Hedged $(1 \sigma)$ & $11 \%$ & $11 \%$ & $6 \%$ & $8 \%$ & $6 \%$ & $6 \%$ \\
\hline Unhedged $(2 \sigma)$ & $5 \%$ & $4 \%$ & $3 \%$ & $5 \%$ & $5 \%$ & $4 \%$ \\
\hline Hedged $(2 \sigma)$ & $5 \%$ & $4 \%$ & $3 \%$ & $3 \%$ & $3 \%$ & $2 \%$ \\
\hline \multicolumn{7}{|c|}{ Pre-crisis } \\
\hline Unhedged $(1 \sigma)$ & $6 \%$ & $4 \%$ & $2 \%$ & $8 \%$ & $6 \%$ & $6 \%$ \\
\hline Hedged $(1 \sigma)$ & $6 \%$ & $8 \%$ & $0 \%$ & $0 \%$ & $0 \%$ & $0 \%$ \\
\hline Unhedged $(2 \sigma)$ & $2 \%$ & $2 \%$ & $0 \%$ & $0 \%$ & $0 \%$ & $0 \%$ \\
\hline Hedged $(2 \sigma)$ & $2 \%$ & $4 \%$ & $0 \%$ & $0 \%$ & $0 \%$ & $0 \%$ \\
\hline \multicolumn{7}{|c|}{ Crisis } \\
\hline Unhedged $(1 \sigma)$ & $6 \%$ & $14 \%$ & $11 \%$ & $20 \%$ & $21 \%$ & $20 \%$ \\
\hline Hedged $(1 \sigma)$ & $10 \%$ & $14 \%$ & $11 \%$ & $11 \%$ & $10 \%$ & $9 \%$ \\
\hline Unhedged $(2 \sigma)$ & $4 \%$ & $5 \%$ & $4 \%$ & $8 \%$ & $6 \%$ & $6 \%$ \\
\hline Hedged $(2 \sigma)$ & $4 \%$ & $6 \%$ & $4 \%$ & $5 \%$ & $4 \%$ & $4 \%$ \\
\hline \multicolumn{7}{|c|}{ Post-crisis } \\
\hline Unhedged $(1 \sigma)$ & $15 \%$ & $8 \%$ & $2 \%$ & $6 \%$ & $8 \%$ & $7 \%$ \\
\hline Hedged $(1 \sigma)$ & $15 \%$ & $8 \%$ & $2 \%$ & $6 \%$ & $5 \%$ & $4 \%$ \\
\hline Unhedged $(2 \sigma)$ & $8 \%$ & $3 \%$ & $1 \%$ & $3 \%$ & $4 \%$ & $4 \%$ \\
\hline Hedged $(2 \sigma)$ & $8 \%$ & $2 \%$ & $1 \%$ & $2 \%$ & $2 \%$ & $0 \%$ \\
\hline
\end{tabular}

Notes: The first two rows in each panel show the probability of a weekly change in MtM larger than one standard deviation of the unhedged portfolio. The last two rows show the probability of a weekly change in MtM larger than two standard deviations. The hedge is estimated each week using a 52-week window.

Table 9: Percent reduction in the variance of weekly MtM changes in CDS and bond portfolios: North American firms (20072018)

\begin{tabular}{|c|c|c|c|c|c|c|}
\hline & \multicolumn{2}{|c|}{ CDS portfolio } & & \multicolumn{2}{c|}{ Bond portfolio } & \\
\hline & Unhedged & Hedged & Variance & Unhedged & & Variance \\
\hline & & & reduction & & & reduction \\
\hline Full sample & $2.38 \%$ & $1.50 \%$ & $60 \%$ & $2.27 \%$ & $1.76 \%$ & $40 \%$ \\
\hline $6 / 2007-5 / 2008$ & $2.18 \%$ & $1.17 \%$ & $71 \%$ & $1.79 \%$ & $1.39 \%$ & $40 \%$ \\
\hline $6 / 2008-12 / 2010$ & $4.11 \%$ & $2.76 \%$ & $55 \%$ & $3.84 \%$ & $2.98 \%$ & $40 \%$ \\
\hline $1 / 2011-6 / 2018$ & $1.40 \%$ & $0.73 \%$ & $72 \%$ & $1.43 \%$ & $1.12 \%$ & $39 \%$ \\
\hline
\end{tabular}

Notes: Mark-to-market variance of the unhedged and hedged portfolios over the full sample and three subperiods. The left panel refers to CDS data, while the right panel refers to corporate bond data. In both cases, data comes from 45 North American CDS firms, as explained in the paper. 
Figure 1: Sectorial linear correlations between sectorial portfolios and credit index: Europe. 2007-2012

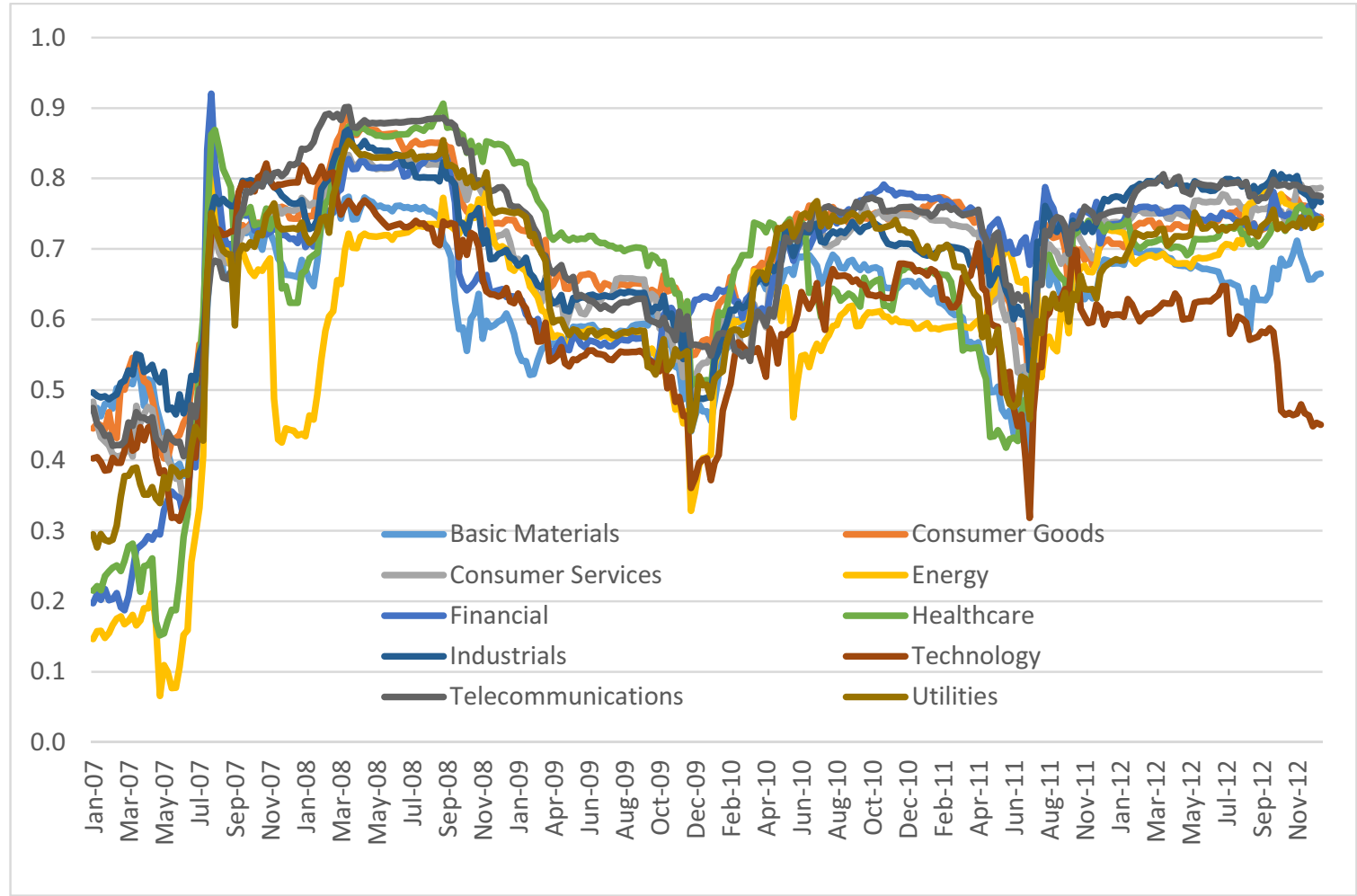

Note: The figure displays the time evolution of sectorial linear correlation coefficients between European firms and the credit index. At each point in time, the graph shows the median correlation for CDS firms in each sector.

Figure 2: Sectorial median beta estimates: Europe. 2007-2012

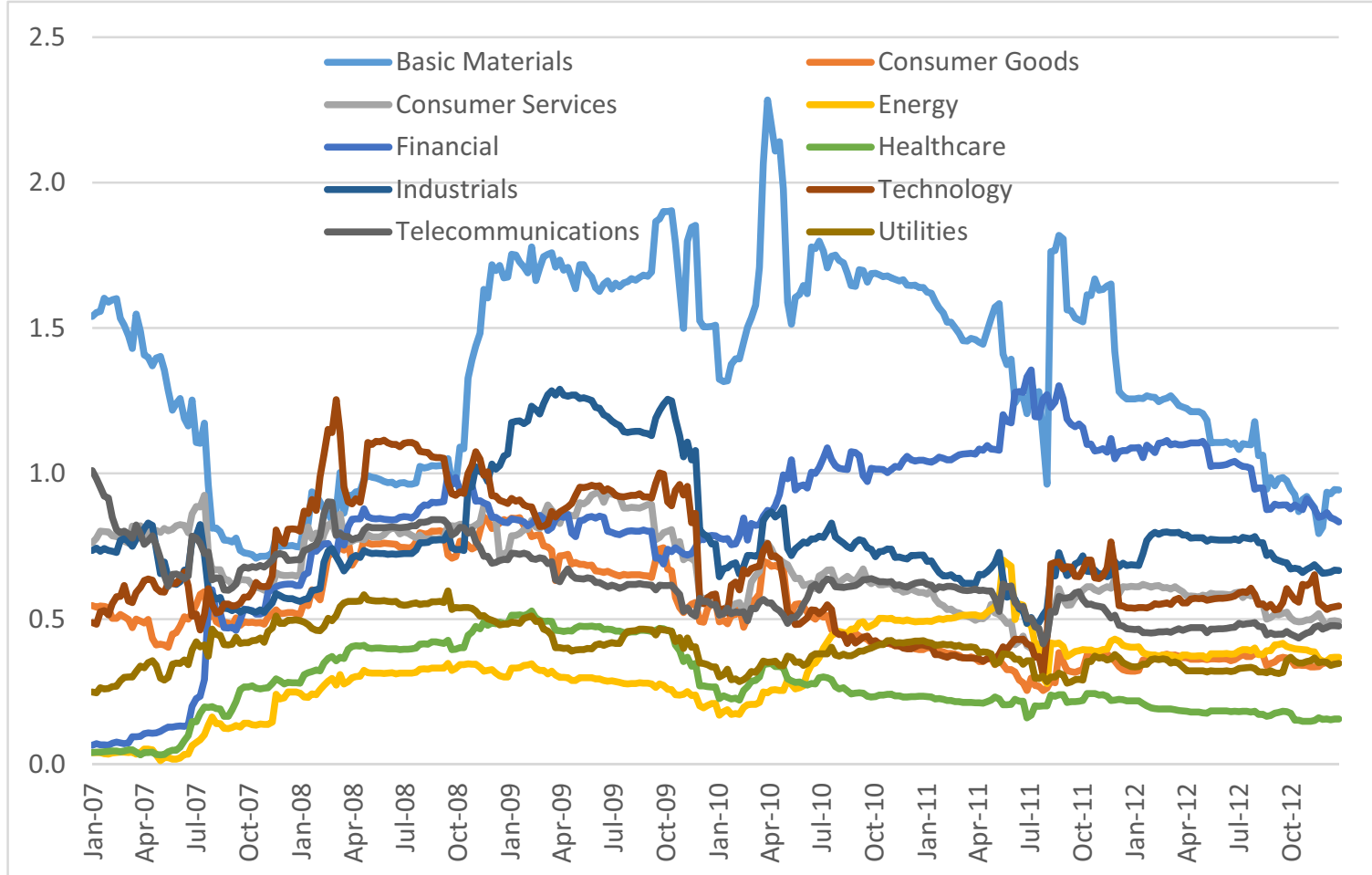

Note: The figure displays the time evolution of sectorial beta estimates for European firms: 2007-2012. At each point in time, the graph shows the median value of beta estimates for CDS firms in each sector. 
Figure 3: Sectorial median beta estimates: North America. 2007-2012

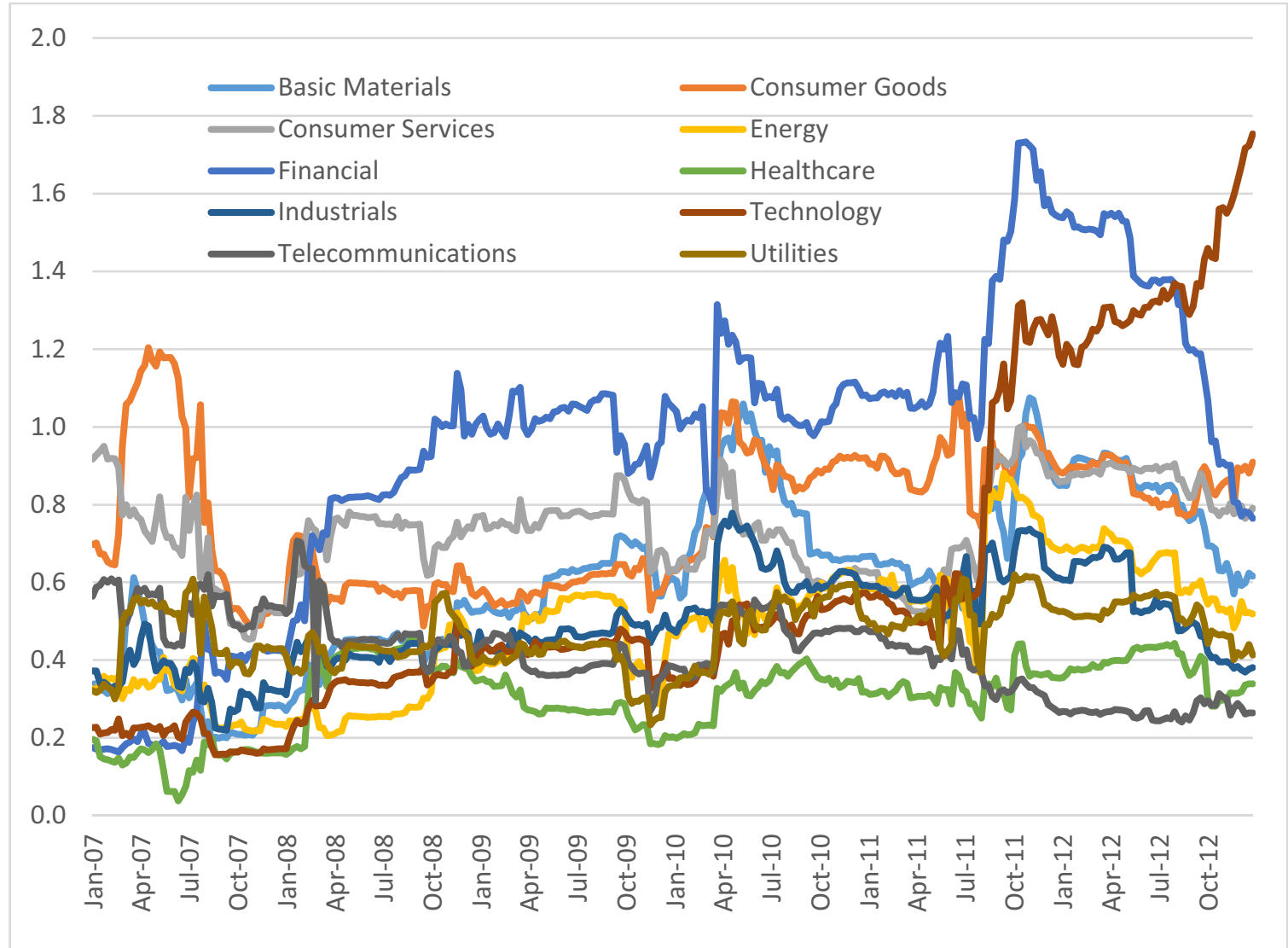

Note: The figure displays the time evolution of sectorial beta estimates for North American firms: 2007-2012. At each point in time, the graph shows the median value of beta estimates for CDS firms in each sector. 
Figure 4: Sectorial linear correlations between sectorial portfolios and credit index: North America. 2007-2012

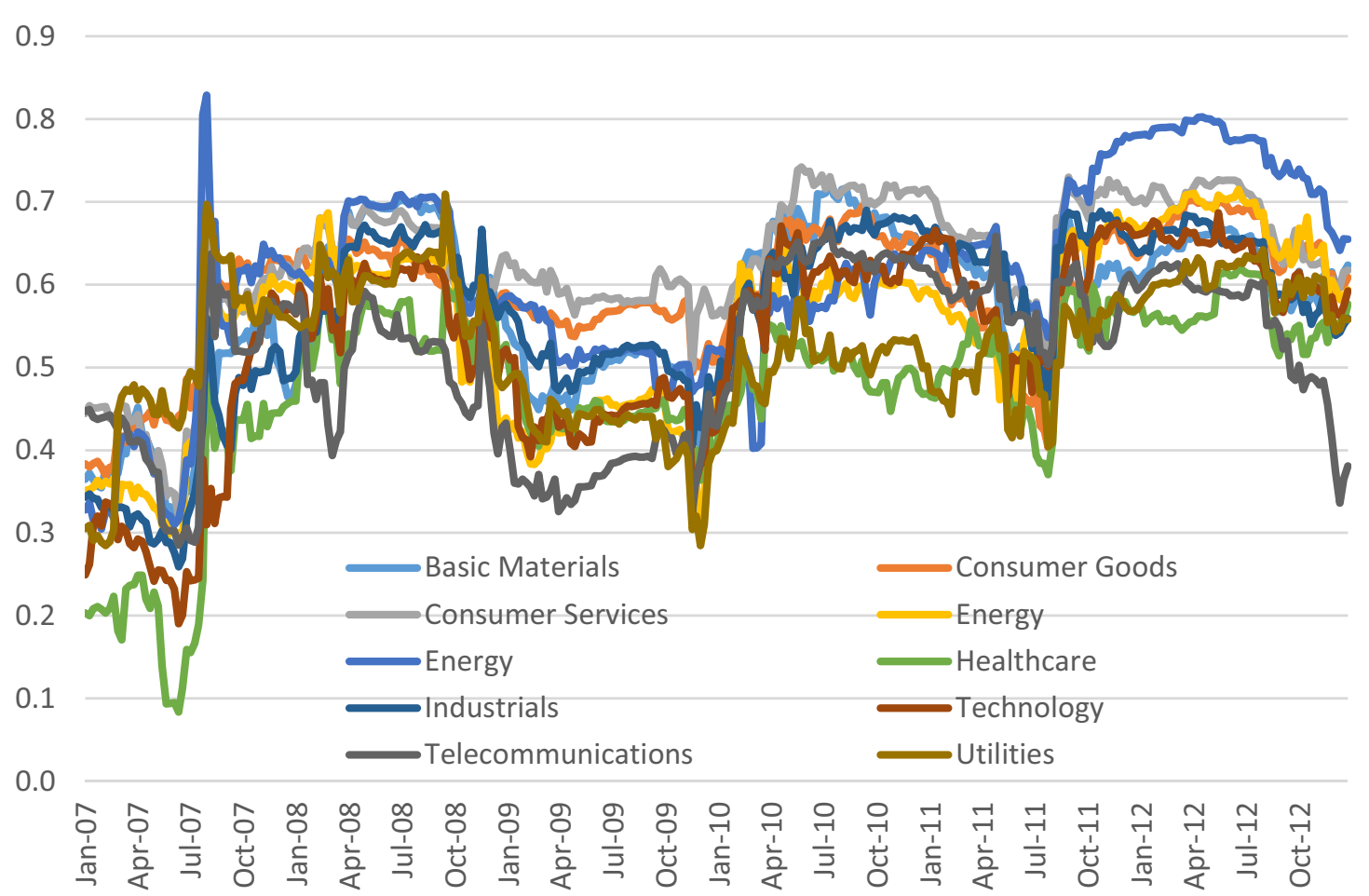

Notes: The figure displays the time evolution of sectorial linear correlation coefficients between North American firms and the credit index. At each point in time, the graph shows the median correlation for CDS firms in each sector.

Figure 5: Weekly profits and losses for the European CDS and hedge portfolios (246 firms) in basis points, 2007-2012

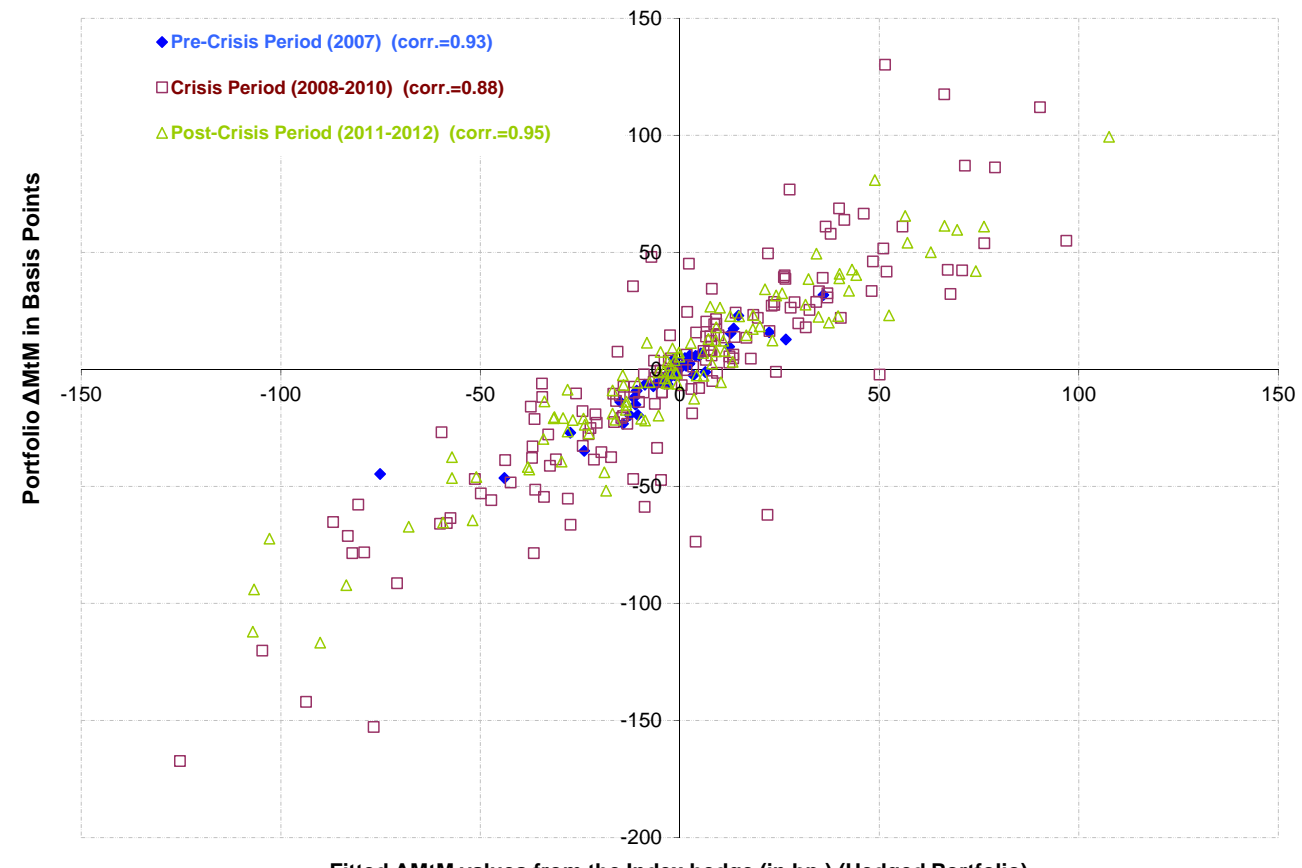

Note: The graph shows a scatterplot of weekly P\&L for the unhedged European credit portfolio and for the hedge portfolio. The latter is obtained as the product of the beta of the credit portfolio by the P\&L of the credit index. A high correlation betwwen them suggests a good hedge. P\&L are shown in basis points (corr.=correlation coefficient). 
Figure 6: Accumulated profits and losses in basis points for the European CDS portfolio (246 firms), 2007-2012

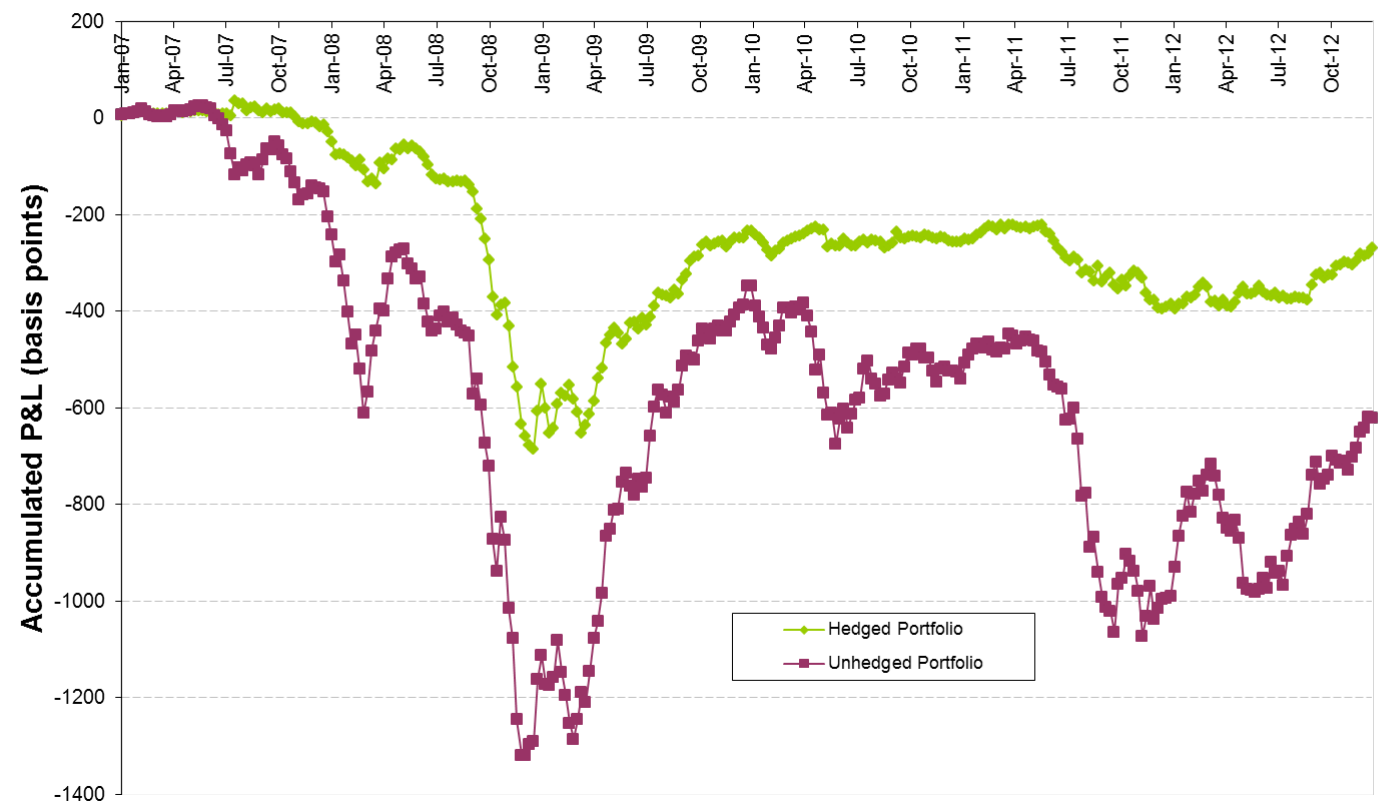

Note: Accumulated P\&L for the unhedged and hedged European credit portfolios since January 2007 in basis points.

Figure 7: Empirical density and distribution functions for weekly P\&L for the European CDS portfolio (246 firms), 2007-2012.

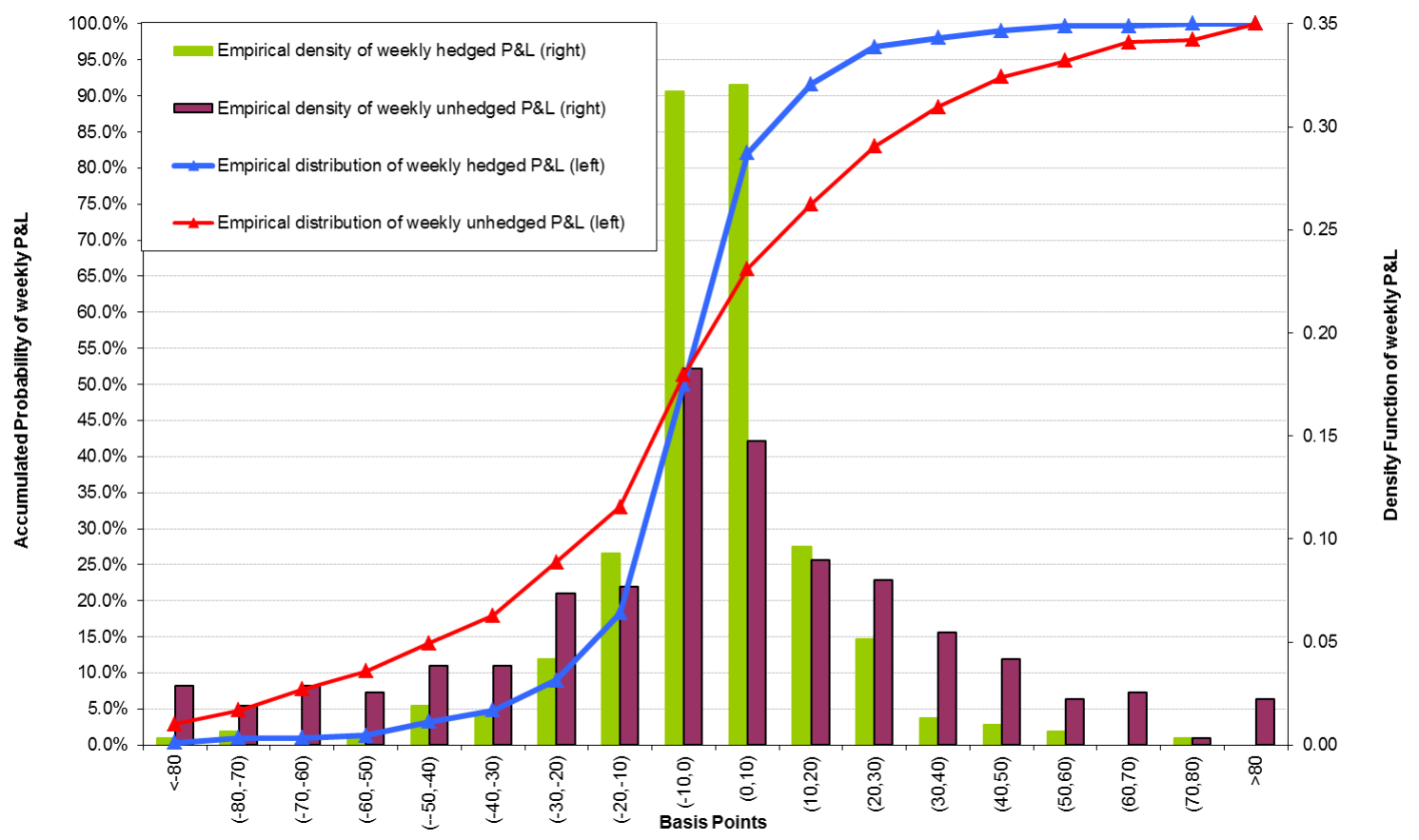

Note: Empirical density and distribution functions for weekly P\&L for the European CDS portfolio: 2007-2012. The two lines display the distribution P\&L functions: the left axis indicates the probability that P\&L are less or equal to the mid-point of each interval in the horizontal axis. The vertical bars show the relative frequency of P\&L in each interval (right axis). 
Figure 8: Weekly profits and losses for the North American CDS and hedge portfolios in basis points. (360 firms), 2007-2012

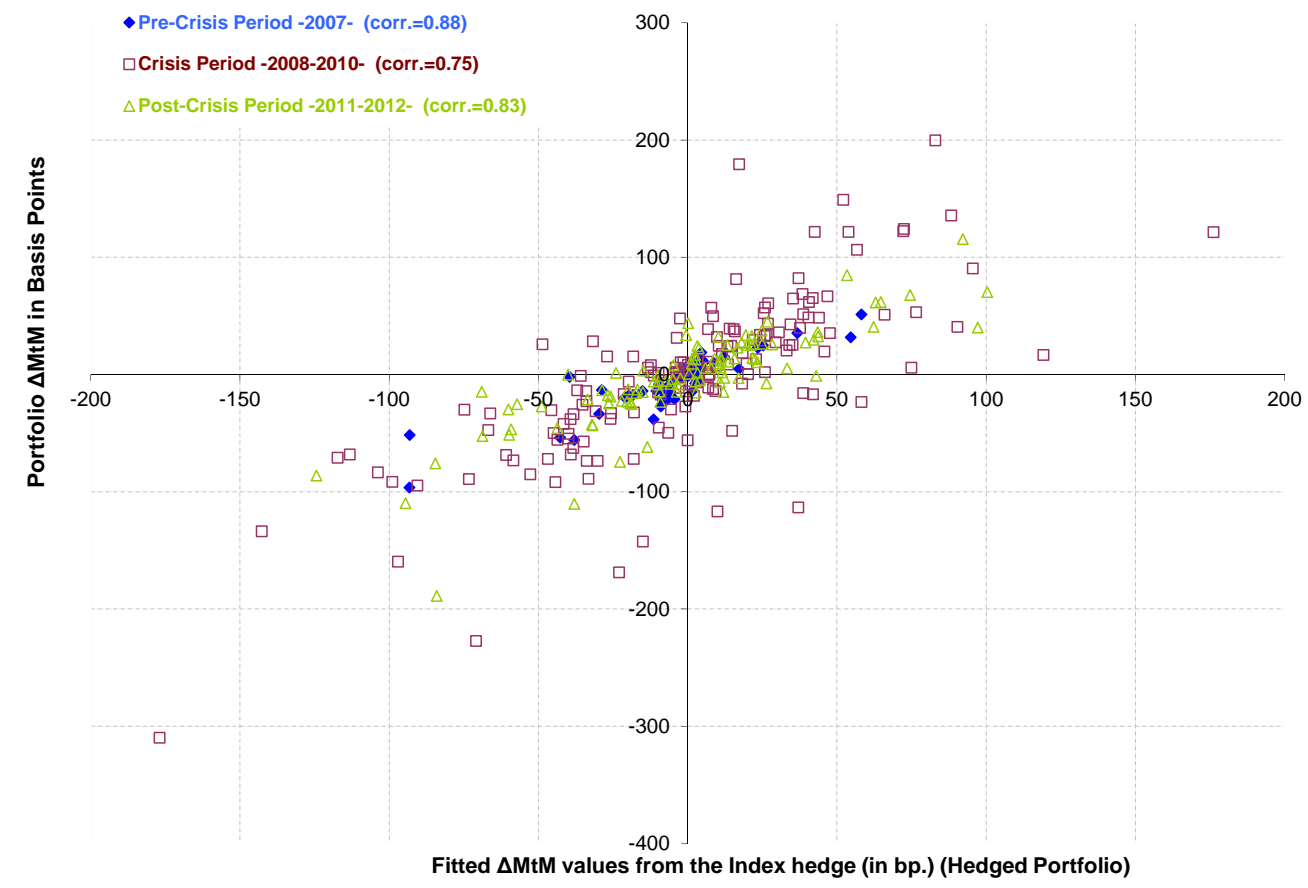

Note: The graph shows a scatterplot of weekly P\&L for the unhedged North American credit portfolio and for the hedge portfolio. The latter is obtained as the product of the beta of the credit portfolio by the P\&L of the credit index. A high correlation betwwen them suggests a good hedge. P\&L are shown in basis points (corr.=correlation coefficient).

Figure 9: Empirical density and distribution functions for weekly P\&L for the North American CDS portfolio (360 firms), 2007 2012

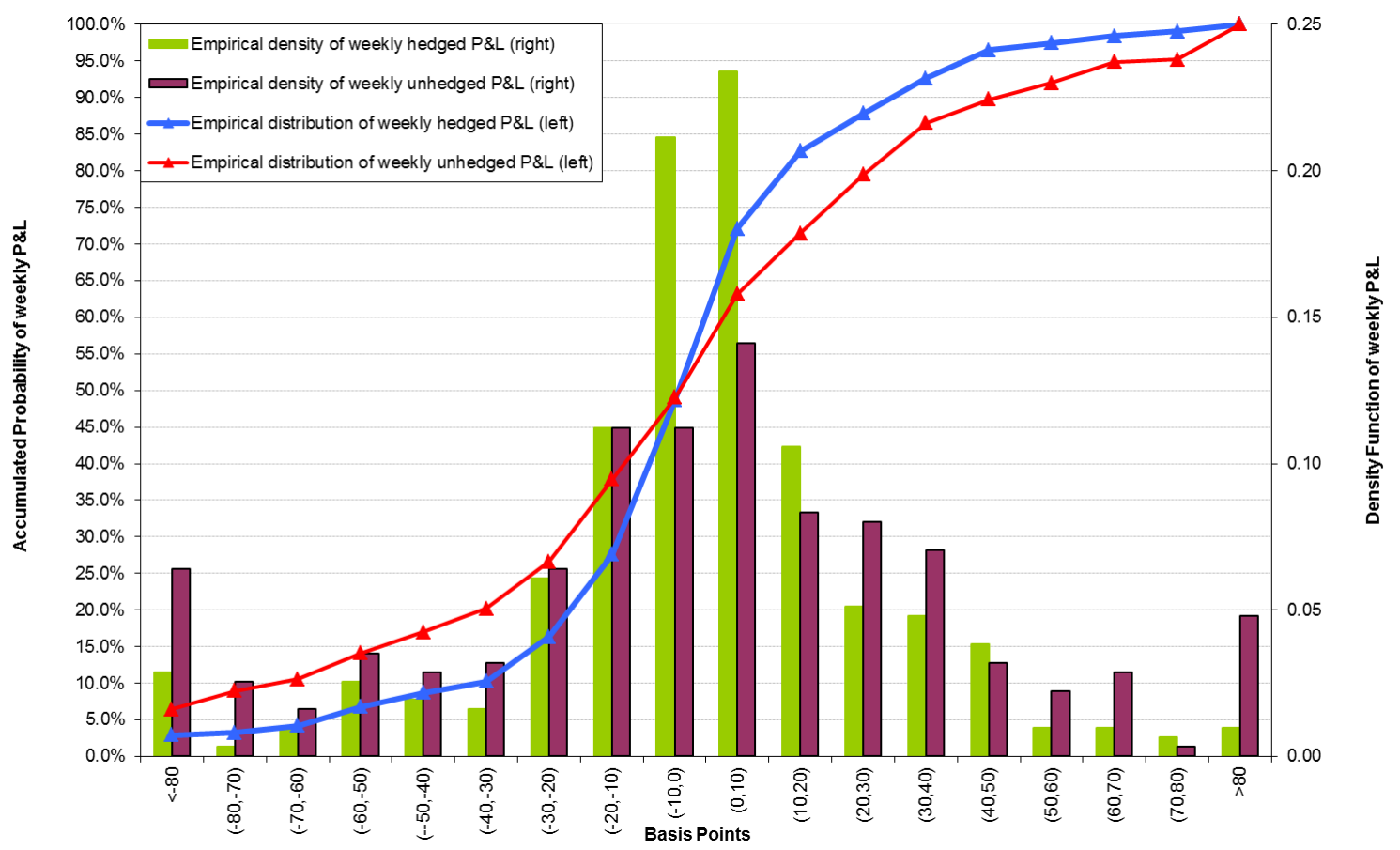

Note: Empirical density and distribution functions for weekly P\&L for the North American CDS portfolio: 2007-2012. The two lines display the distribution P\&L functions: the left axis indicates the probability that P\&L are less or equal to the midpoint of each interval in the horizontal axis. The vertical bars showthe relative frequency of P\&L in each interval (right axis). 
Figure 10: Accumulated profits and losses in basis points for the North American CDS portfolio. (360 firms), 2007-2012

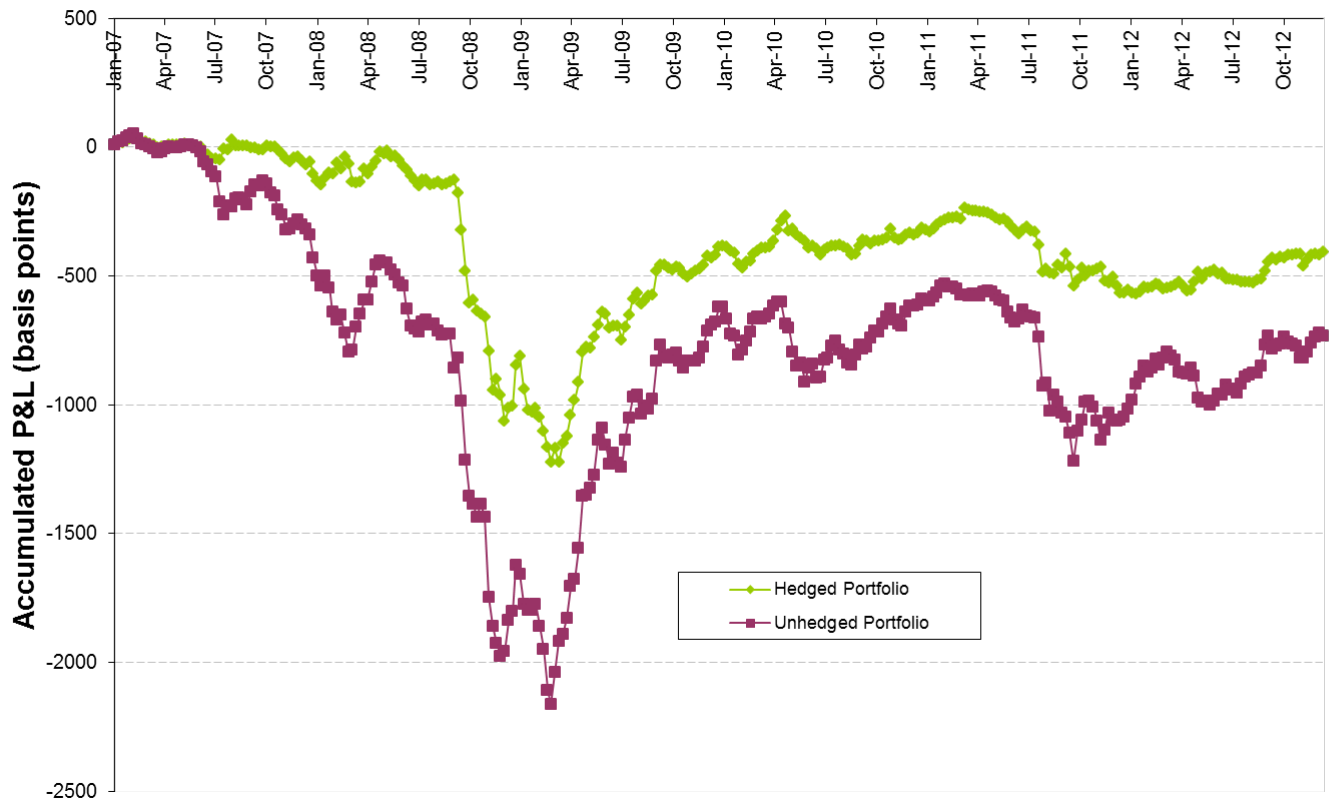

Note: Accumulated P\&L for the unhedged and hedged North American credit portfolios since January 2007 in basis points.

Figure 11: Percent reduction in MtM variance as a function of the size of the portfolio

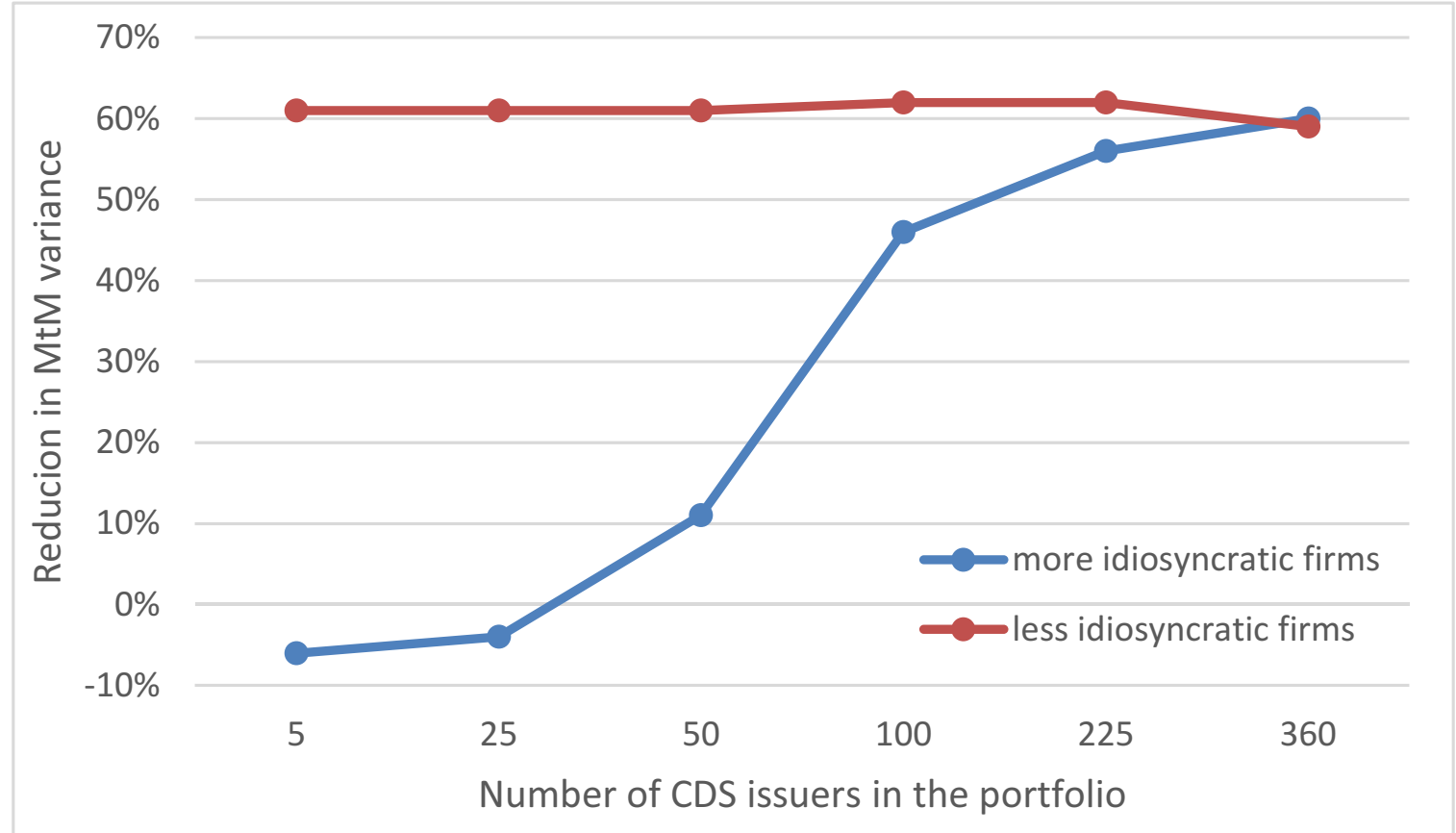

Note: The graph shows the estimated reduction in MtM variance from hedging a portfolio of North American CDS firms with a contrary position in the CDX index, as the number of firms included in the portfolio increase. The red line corresponds to portfolios made up of the less idiosyncratic firms, while the blue line corresponds to portfolios made up of the more idiosyncratic firms. 
Figure 12: Volatility: hedged and unhedged portfolio of 360 North Amerian firms

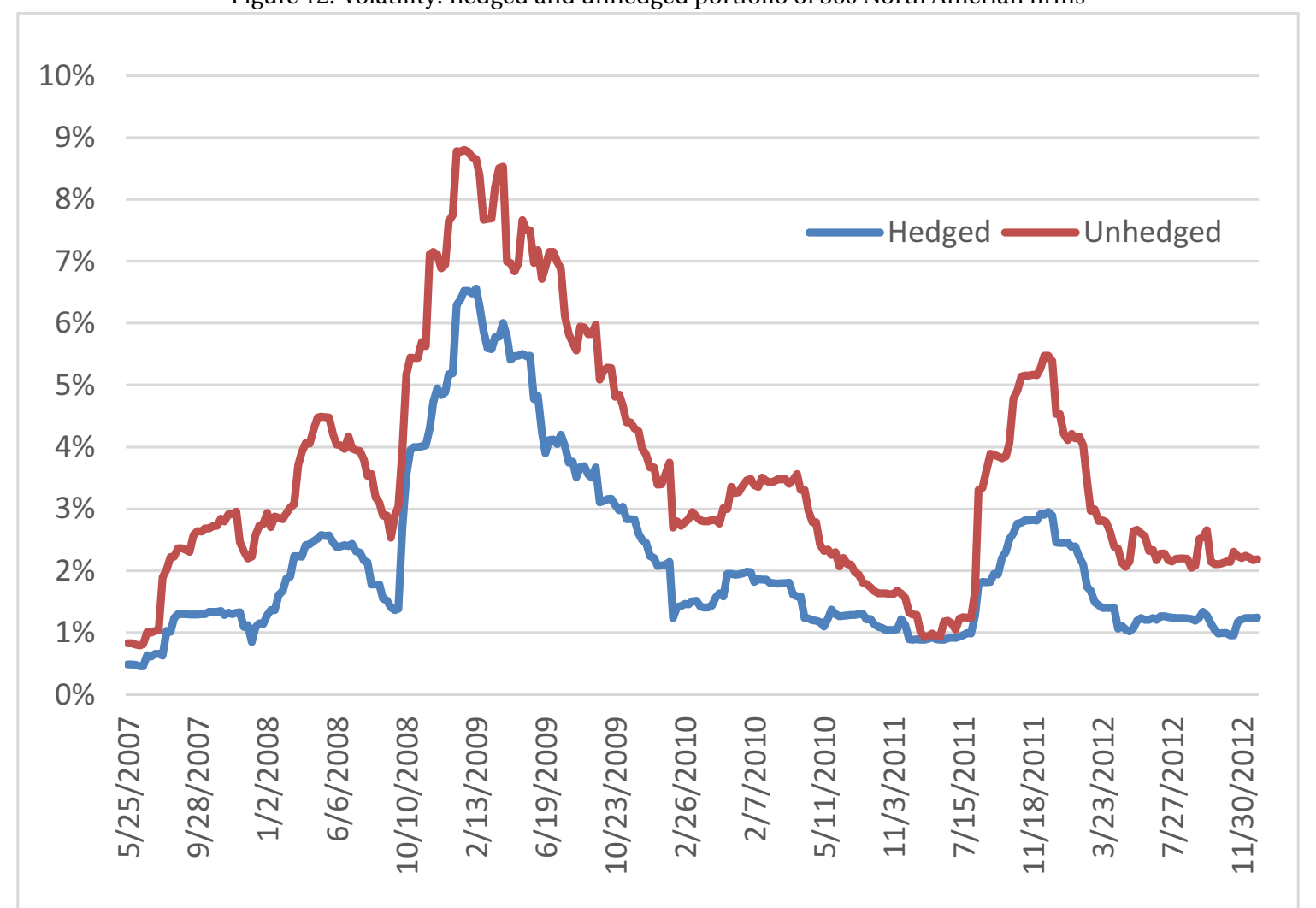

Note: Annual volatility (annualized standard deviation) of the unhedged and hedged portfolios made up of the 360 North American firms: 2007-2012. 
Figure 13: CDS and Bond Volatility: hedged and unhedged 45-firm portfolio

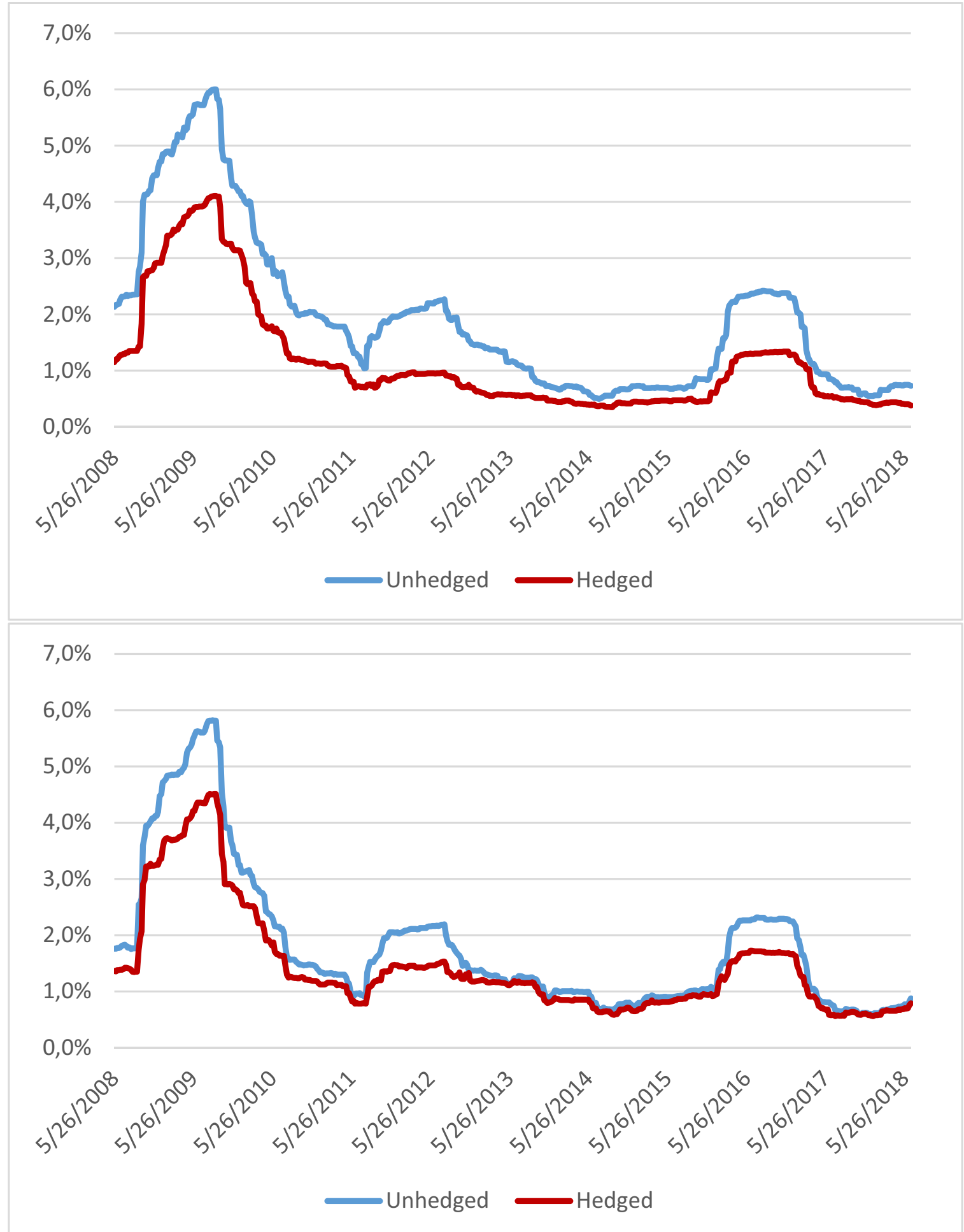

Note: The first figure shows the annual volatility (annualized standard deviation) of the unhedged and hedged portfolios made up of the 45 firms: 2008-2018. The second figure shows the annual volatility (annualized standard deviation) of the unhedged and hedged portfolios made up of the same 45 firms: 2008-2018. 